\title{
A!
}

This is an electronic reprint of the original article.

This reprint may differ from the original in pagination and typographic detail.

Seregina, Anastasia; Weijo, Henri

\section{Play at Any Cost: How Cosplayers Produce and Sustain Their Ludic Communal Consumption Experiences}

Published in:

Journal of Consumer Research

DOI:

10.1093/jcr/ucw077

Published: 01/01/2017

Document Version

Peer reviewed version

Please cite the original version:

Seregina, A., \& Weijo, H. (2017). Play at Any Cost: How Cosplayers Produce and Sustain Their Ludic Communal Consumption Experiences. Journal of Consumer Research, 44(1), 139-159.

https://doi.org/10.1093/jcr/ucw077

This material is protected by copyright and other intellectual property rights, and duplication or sale of all or part of any of the repository collections is not permitted, except that material may be duplicated by you for your research use or educational purposes in electronic or print form. You must obtain permission for any other use. Electronic or print copies may not be offered, whether for sale or otherwise to anyone who is not an authorised user. 


\title{
Play at Any Cost: How Cosplayers Produce and Sustain Their Ludic Communal
}

\section{Consumption Experiences}

\author{
ANASTASIA SEREGINA ${ }^{1}$
}

HENRI WEIJO ${ }^{2}$

\begin{abstract}
${ }^{1}$ Anastasia Seregina (anastasia.seregina@aalto.fi) is a Postdoctoral Researcher at Aalto University School of Business, Department of Marketing, P.O. Box 21230, 00076 Aalto, Finland.

${ }^{2}$ Henri Weijo (hweijo@bentley.edu) is Assistant Professor in Marketing at Bentley University, 175 Forest St., Waltham, MA, USA, 02452 and visiting professor at Aalto University School of Business.
\end{abstract}

This manuscript is the result of a truly collaborative endeavor. The authors are listed alphabetically. The authors thank the informants for their willingness to share their fascinating personal stories. We also thank John Schouten, Jeff Murray, Russell Belk, Amber Epp, and George Ritzer for their helpful comments at different stages of the preparation of this manuscript. Last, we thank JCR's insightful reviewers, tireless associate editor, and extremely supportive editor. Their dedication and participation throughout the review process proved truly invaluable. 


\title{
Contribution Statement
}

Our research provides new insights into how consumers maintain ludic communal consumption engagements when faced with temporal, economic, emotional, and competencerelated obstacles. We present a set of practices that consumers use to stabilize performances and remain engaged in communities. Our work further extends previous literature on play and ludic experiences, consumption community engagement, identity costs, and consumption practices. Lastly, our findings extend understanding of boundary management among leisure and other practice circuits, communal hybrid economies, value, as well as the use of social media in consumption communities.

\begin{abstract}
Communal consumption remains a staple topic for consumer research. Previous studies have often described communal consumption as inherently playful. Yet previous works have mainly focused on successful ludic communal experiences with less regard to potential pitfalls. Moreover, prior research has emphasized marketer facilitation of ludic experiences while marginalizing consumers' orchestrating role. This paper explores how consumers produce and sustain ludic consumption community experiences in the face of growing instrumental costs to communal engagement. We build theory though an ethnographic inquiry of cosplay, a time and resource intensive form of pop culture masquerade and craft consumption. Our practice-theoretical analysis provides insight to prolonged engagement in the cosplay community leading to growing emotional, material, temporal, and competencerelated costs. We show how cosplayers use practices modularization, reinforcement, and collaboration to maintain the ludic sensations that make communal engagements meaningful.
\end{abstract}


Communal consumption remains a central topic for cultural consumer research and has produced an impressive research corpus (Arnould and Thompson 2005). Previous studies reiterate that consumers often develop lasting social ties with fellow community members and make the communal cause central to their identities (e.g., Celsi, Rose and Leigh 1993; Schouten and McAlexander 1995; Kates 2002). Such research also shows that communal engagements are highly enjoyable for consumers. More specifically, ludic consumption, or play, is seen as inherent to many consumer pursuits to find leisurely contrast to everyday practices in communal consumption settings (e.g., Arnould and Price 1993; Celsi, Rose and Leigh 1993; Schouten and McAlexander 1995; Belk and Costa 1998; Kozinets 2001; 2002; Martin and Schouten 2014; Thompson and Üstüner 2015).

The appeal of communal consumption and its potential to foster ludic experiences has been well documented. Yet previous research also features sporadic examples of play breaking down at various stages of the communal experience (Belk and Costa 1998; Kozinets 2002; Tumbat and Belk 2011; Woermann and Rokka 2015). Attaining ludic experiences is thus not a guaranteed outcome in communal consumption. Moreover, the successful orchestration of ludic experiences has usually been attributed to the marketer, particularly through meticulous servicescape design (Arnould and Price 1993; Kozinets et al. 2004; Tumbat and Belk 2011; 2013; Woermann and Rokka 2015). The role of the consumer in facilitating play within communal consumption has received little research interest. Thus, the purpose of this paper is to uncover how consumers produce and sustain ludic consumption community experiences in the face of increasing instrumental costs.

We conducted our research in the North American context of cosplay, which is a form of pop culture craft consumption and masquerade. Our ethnographic inquiry found cosplay to be a ludic and enticing communal activity with endless advancement opportunities. However, cosplayers faced growing instrumental obstacles to their communal engagement, which often 
compromised the fun factor. First, the servicescapes that cosplayers primarily occupy proved to be a less than ideal spatio-temporal stages for ludic experiences. Second, cosplayers' immersion into the community brought with it significant temporal, material, and emotional demands. We illustrate how consumers mitigated these obstacles to their ludic communal consumption experiences via practices of modularization, reinforcement, and collaboration.

The paper is structured as follows. We begin by reviewing prior literature on ludic experiences in communal consumption. We then elaborate on our analytical lens of practice theory (Schatzki 2002; Shove, Pantzar, and Watson 2012). Next, we present the context of our study, cosplay, and our methodological procedures. Our findings unfold in the three sections that follow. First, we elaborate on the practices and ludic elements of cosplay. Second, we illustrate the costs of maintaining communal engagement. Third, we outline the consumer practices that maintain ludic communal engagement. We conclude the paper with a theoretical discussion and suggestions for future research.

\section{LUDIC EXPERIENCES IN COMMUNAL CONSUMPTION}

\section{A Brief Overview of Ludic Experiences and Play}

Play is a complex socio-cultural phenomenon with a nebulous conceptual history (Grayson 1999; Kozinets et al. 2004; Malaby 2009). Most famously, Huizinga (1949) defined play as a voluntary, captivating, and unserious activity that resides outside of or in contrast to ordinary life. Play is a natural human activity that involves no material interests and promotes learning as well as the formation of social groups (Caillois 1961; Schechner 1988). Play becomes the antithesis of efficacy and utilitarianism, a purely hedonic pursuit 'for its own sake' (Holbrook et al. 1984). However, Huizinga (1949) also stressed play to be extremely 
ordered and distinct from other activities. Because of this, play usually takes place in specific spatio-temporal contexts, or ludic stages, that are more conducive to play than others (e.g., Huizinga 1949; Turner 1982; Schechner 1988). Hence, play is both freeform and structured. Huizinga (1949) saw modernity weaning out play via its division of work and leisure as well as in the idealisation of productivity. Play became seen as inconsequential makebelieve and a stigmatised activity for adults: unserious and unimportant (Huizinga 1949; Goffman 1959; Schechner 1988; Saler 2012). In an extreme characterization underlining this non-utilitarian view, Caillois (1961) dubbed play an activity of "pure waste: waste of time, energy, ingenuity, skill and often money" (125). However, modernity's economic, social, and technological developments also helped democratize leisure and facilitated consumer access to it (Rojek 2010; Saler 2012). Still, only specific areas, such as popular culture (Saler 2012) or entertainment servicescapes (e.g. Ritzer 1999; Sherry 1998; Kozinets et al. 2004), became sanctioned spaces for mature individuals to play in.

These perspectives on play as irrational, inconsequential, and unproductive are in line with the modernist idea of 'Homo Faber,' that is, the working man (Huizinga 1949). This perspective saw play as a utopia of release and freedom, a reward for hard work (Rojek 2010). In such a worldview, there is no play outside of leisure (Rojek 1995). However, play is often rational and enmeshed in market activity, thus complimenting work through extending personal market capacity. A more postmodern perspective on play follows the perspective of 'Homo Ludens,' that is, the playing man (Huizinga 1949; Rojek 1995). Here, play is a necessary human activity found in many social domains (see Sennett 2008). In this view, work and play become co-constituting and historically mutable concepts, resulting in fluctuating boundaries between play and not-play (e.g., Turner 1982; Schechner 1988; Rojek 1995). For example, in Western contexts work has recently become more playlike for some 
(e.g., Sennett 2008; Arnould and Press 2011), while play has become more worklike for others (e.g., Stebbins 1982; Belk and Costa 1998; Rojek 2010).

Though the boundaries of play are difficult to discern (Grayson 1999), theorists tend to agree on one important aspect: play is ultimately an emotional experience (e.g., Huizinga 1949; Holbrook and Hirschman 1982; Holbrook et al. 1984), a source of "joy and amusement" (Caillois 1961, 125). In other words, regardless of its form, play needs to feel like play. Moreover, play requires commitment and appreciation of the activity; as Huizinga (1949) wrote, it is not the cheat, but the spoilsport that ruins play by ignoring and displacing its rules. This mutual appreciation of play-acts is important for inducing communion (Arnould and Price 1993; Holt 1995; Kozinets et al. 2004).

Play also often promotes and necessitates mastery and learning (Holbrook and Lehmann 1981; Rojek 2010; Unger and Kernan 1983). Though no two instances of play are ever similar (Malaby 2009), continuous learning staves off loss of interest that ensues when play activities that were once thrilling become routine (see Woermann and Rokka 2015).

\section{Ludic Consumption and Consumer Orchestration of Communal Experiences}

Play features pervasively across consumer behavior (Holbrook et al. 1984; Holt 1995; Grayson 1999). It is one of the defining elements of an idealized leisure experience (Holbrook and Lehmann 1981; Rojek 2010; Unger and Kernan 1983). Play facilitates consumer interaction within shared spatio-temporal settings (Holt 1995; Belk and Costa 1998; Kozinets et al. 2004). Ludic experiences are particularly central to communal consumption (Celsi et al. 1993; Kozinets 2002). The joyous solidarity, intrinsic rewards, and visceral thrills inherent to many communal experiences explain how communities persists over years or even decades, and why consumers make communal fidelity central to their 
identities (e.g., Arnould and Price 1993; Celsi et al. 1993; Schouten and McAlexander 1995; Belk and Costa 1998; Kozinets 2002; Martin and Schouten 2014).

Tumbat and Belk (2013) note that previous research has presented the orchestration of ludic experiences primarily as a responsibility of marketers. For example, marketers often encourage play through meticulous design of servicescapes (Sherry 1998; Ritzer 1999; Kozinets et al. 2004; Maclaran and Brown 2005; Otnes et al. 2012). Marketer facilitation of play can also be explicitly meant to induce communion. Arnould and Price (1993) show how river rafting guides invite rafters to play through pre-organized games during the extended service encounter. Such experiences endorse communitas, enjoyment, and self-development, but do require the consumers to be willing and active participants in the experience (e.g., Grayson 1999; Otnes et al. 2012). Yet Tumbat and Belk (2013) point out that studies usually limit consumers' orchestration of communal experiences to influencing only the symbolic, verbal, or emotional aspects of the experience. They further write that previous research tends to romanticize communal settings and ignore potential practice failures and negative communal dynamics. As a result, "performative competencies of participants are taken for granted. It is as if in these co-created experiences there is nothing at stake and success is pretty much guaranteed" (p. 50).

Prior works provide sporadic examples of concern over the failure of play. For example, Kozinets (2002) describes how participants' playful displays at Burning Man can become overtly competitive and threaten communal ethos. Tumbat and Belk (2011) similarly show that when consumer goals and interactions are mutually exclusive, extraordinary consumption experiences do not induce play or communion. Prior works also provide hints on how communities might work together to make play happen. For example, senior members educate new members on proper performances of communal practices to ensure communal meanings are not devalued (Schouten and McAlexander 1995; Schau et al. 2009; 
Arsel and Thompson 2011). This bears similarities to how social consensus of play-rules emerges from teaching others how to play (Huizinga 1949; Caillois 1961). However, becoming proficient in communal practices may entail significant time and material investments that can complicate engagement. Previous community research has made note of such rising demands (Celsi et al. 1993; Belk and Costa 1998; Tumbat and Belk 2011). Yet the full impact of such instrumental considerations to ludic communal experiences has not been explored.

To sum up, it is evident that play is central to consumption and especially to communal consumption. However, previous research has focused on marketer orchestration, successful ludic experiences, as well as viewed ludic experiences as inherent to communal consumption. But ludic experiences can fail to emerge (Tumbat and Belk 2013). This papers aims to uncover how ludic communal experiences are orchestrated and sustained by consumers themselves in the face of growing instrumental costs. We tackle this question using practice theory.

\section{Exploring Ludic Experiences through Practice Theory}

Practice theory views social life through shared and routinized performances of embodied and materially interwoven practices (Schatzki 2002; Warde 2005). This study adheres to Shove et al.'s (2012) breakdown of three co-constituting practice elements: competence, material, and meaning. Competence refers to the skills and know-how of a practice. Material is the things, tools, technologies, spatio-temporal geography, and physical body within a practice. Meaning, also called the teleoaffective structure, refers to a practice's symbolic, homologically shared, emotional, and aspirational ends (Schatzki 1996). These shared emotional and aspirational ends organize the flow of practice performances. As 
Malaby (2009) writes, this makes practice theory ideally suited for studying ludic experiences, given the centrality of emotions in making play feel like play.

Practice theory further posits that practice performances entail stabilizing acts of limited spontaneity to stabilize misaligned practice routines (Schatzki 2002; Warde 2005). In a recent study, Woermann and Rokka (2015) illustrate how different practice elements - such as materials, rules, understandings, and procedures - have to be properly aligned in two ludic activities, free-skiing and paintball, to produce the desired emotional ends of fun, flow, and accomplishment. A misalignment of practice elements results in the experience feeling either dragging or rushed. Our analysis similarly focuses on consumer efforts to realign practice elements to sustain the ludic sensations that make practice performances meaningful.

In our view, an appropriate context for studying how consumers produce and maintain ludic communal experiences would meet the following criteria: (1) marketers do not look to proactively orchestrate ludic experiences; (2) the activity is fulfilling and thus not easily abandoned; and (3) engagement results in monetary, material, or emotional costs. As we show next, our research context of cosplay readily satisfies all conditions.

\section{CONTEXT: COSPLAY AND THE CON CIRCUIT}

Cosplay, short for 'costume play,' is the practice of crafting outfits (including relevant make-up, hair, and props) based on popular culture source material and wearing them at related events, namely comic book conventions, or 'cons.' Cosplay spun off from the costumed role-playing circles of the 1960s into its own activity at comic book and anime conventions (Winge 2006). Costume building draws inspiration mostly from 'geek culture,' that is, the increasingly popular consumption field of superheroes, sci-fi, fantasy and their related franchises of movies, TV-shows, comic books, and video games (Jenkins 2012). We 
emphasize that cosplay is inherently different from costumed activities like live action roleplay (Seregina 2014) or historical re-enactment (Belk and Costa 1998). These activities entail character immersion and story engagement. Hence, costumes are supportive performance elements and their quality is secondary to the storyline and/or interaction. Conversely, in cosplay, highly elaborate costumes are the most central aspect in the practice.

Cosplayers are usually young, ranging from teens to those in their early thirties (Gunnels 2009; Jenkins 2012). Though we encountered cosplayers with working class backgrounds, we assert that the majority of cosplayers are from college-educated middle class families with mid-level cultural capital, much like Arsel and Thompson's (2011) context. A fan portraying a favorite character is a common cosplay initiation story (Gunnels 2009; see Kozinets 2001). Many cosplayers with whom we interacted also had a priori socialization into dress-up and costuming through friends or family, particularly through events like renaissance fairs. Halloween was frequently referenced in our fieldwork as a favorite holiday, as were long-standing family traditions of Halloween costume preparation.

Cosplay proportionally attracts more women (Winge 2006), even though geek culture overall is notably male dominant (Scott 2013). We believe this can be explained by two characteristics of the practice. First, primary skills required for costume crafting, such as sewing and make-up artistry, are stereotypically considered more feminine, which may discourage male cosplayers. Second, cosplay has emerged as an avenue for fan identity politics and a way for women to proclaim legitimacy in the male dominated geek culture. This becomes especially evident in a form of cosplay called 'crossplay,' in which fans portray characters of a different gender. Women exercise crossplay much more frequently than men do and often frame the practice as a challenge to geek culture's male stereotypes (Winge 2006). Crossplay has also been shown to provide escapist experiences from everyday anxieties relating to sexuality and body image (Winge 2006; Gunnels 2009). 
Cosplay involves two constituting practices: performing in costumes and crafting costumes. Both are conducive to play. Performing in costume brings evident contrast to everyday practices (Huizinga 1949; Belk and Costa 1998), whereas craft is playfully immersive and improvisational (Watson and Shove 2008; Sennett 2008). The relationship between crafting a costume and performing in costume speaks to Goffman's (1959) depiction of front stage and back stage activities; costume crafting in private settings facilitates playful dress-up performances in public, communal stages.

Cosplay is highly time-consuming and costly (Gunnels 2009). Outfits can take multiple months or even years to build, with potential costs reaching thousands of dollars. Growing temporal and monetary demands in cosplay invariably become problematic. Thus, we see cosplay as an ideal context for studying how ludic communal experiences are produced and sustained when consumers are faced with increasing instrumental costs.

\section{METHODOLOGICAL APPROACH}

We studied cosplayers' communal engagements using ethnographic inquiry. This allowed us to observe social and cultural phenomena as well as shared meaning systems through lived experience and as part of their cultural context (Arnould and Wallendorf 1994). The first author initially learned about cosplay by attending cons in Finland during 2012 and 2013. Between 2013 and 2016, the authors collected data by attending conventions in the US individually and together. Altogether, we attended eleven conventions, which varied from localized gatherings of approximately 3,000 people, to international events of over 150,000 people. The events spanned from two to seven days. Both authors have backgrounds in studying geek culture, which facilitated contextual understanding. 


\section{$<<===$ INSERT TABLE 1 AROUND HERE $===>>$}

During the conventions, we engaged in ethnographic observation of cosplay and related activities that we recorded with field notes and photographs. We interacted with hundreds of cosplayers and conducted recorded formal and unrecorded informal interviews. In total, we recorded 64 interviews, which ranged from short five-minute ethnographic interviews probing costume details to long interviews lasting over one and a half hours. We also followed up with some of our informants via email and their personal webpages. For our interviews, we purposefully sought out cosplayers of various ages, skill, and engagement levels. As a result, the interviewees ranged from complete novices to avid enthusiasts and even professional cosplayers. The authors represent both genders, which proved helpful: interviewees were more willing to disclose personal details to persons of the same gender. Consequently, we interviewed cosplayers individually and together, depending on the situation. The recorded interviews were transcribed verbatim.

In addition to our ethnographic fieldwork, we conducted an extensive netnography (see Kozinets 2010) in one of the biggest online communities for cosplay (cosplay.com), which our informants frequently referenced. Cosplay.com became instrumental to familiarizing ourselves with cosplay culture. Both authors became members of the online community and announced their presence to the membership. In all, we analyzed 138 discussion threads that prompted dozens to hundreds of replies from community members. Our growing competence with cosplay lingo, coupled with our earlier ethnographic fieldwork findings, allowed us to purposively sample and pursue negative cases within the community's archives (Miles and Huberman 1994). We also went outside of cosplay.com and incorporated data from blogs and communities connected to cosplay.com. Most likely due to the anonymity of the interaction, we witnessed more revealing accounts than during 
interviews (cf. Kozinets 2010). This supported our ethnographic and interview data, aided our understanding of our observations, and helped us find themes to explore and to exclude. The netnographic data was central to refining and finalizing our research themes.

Our initial research purpose focused on understanding fan practices and creativity, but as the research evolved, our informants' difficulties in maintaining engagements emerged as strong themes. Hence, we shifted our focus on said themes. Our ethnography and netnography were both continuously refined and adjusted with the help of existing literature (Spiggle 1994). In the following text, we use interview and netnographic excerpts to represent our data. All individuals have been given pseudonyms to ensure their anonymity. All excerpts are from interviews unless noted otherwise in the citation.

In investigating cosplay's practice circuit, we distinguished between its material, competence, and meaning elements (Shove et al. 2012). To reiterate, material refers to the relevant objects, tools, infrastructure, spaces, and practitioners' bodies used in the practice. Competence is the relevant shared skills, knowledge, and understandings of the practice. Meaning refers to the shared symbolic, emotional, and aspirational ends that govern practice performances. We analyzed our data by means of hermeneutical analysis, which involved an iterative process of interpretation and reinterpretation that aims to develop a sense of the whole (Arnold and Fischer 1994). Our data are summarized in Table 1. Throughout the research, we moved between different data sources as well as units and levels of analysis. The two authors continuously compared individual data readings to ensure analytical rigor.

\section{THE PRACTICE OF COSPLAY}

To reiterate, the overall practice of cosplay is made up of two co-constituting sub-practices: crafting the costume and performing in the costume at cons. Informant accounts illustrated a 
ludic orientation to both crafting and performing. Brad provided a typical narrative: "I cosplay because I need something to do besides work... I always feel so proud of myself when I finish even one piece of a costume, and hanging out with other geeks for a weekend is awesome. It's my annual vacation.” Brad evokes prototypical ludic elements: leisurely separation, intrinsic enjoyment, and communion. Ariana (cosplay.com) provided another example: "there are no rules [in cosplay]. If anyone tells you any differently, they are either elitist or selling something. Do what you want, have fun.” Ariana's 'anything goes' view shuns "elitists" and profiteering motivations, linking to ludic ideals of freedom (Caillois 1961) and anti-structure (Arnould and Price 1993). Senior cosplayer Ivy similarly encouraged attendants of a 'Cosplay 101' con panel discussion: "as long as you like the character, that's all what matters. It's about having fun.”

Despite this emphasis on freedom, costume crafting and performing do feature implicit rules and understandings that structure ludic experiences. In this section, we first describe the practice of crafting increasingly elaborate costumes. We then focus on performing in costume and ludic character interaction at cons.

\section{Immersive Crafting of the Perfect Costume}

The Costume Crafting Project. A costume project invariably begins with meticulous planning. Cosplayers rely heavily on character representations from source media, such as movies, comic books, and fan art, in figuring out costume compositions. For example, when starting to work on his Captain America costume, Cody was "watching the movie like 10 times over and pausing it and like looking at like where they got this made and such."

Insight into geek culture canon represents subcultural capital that allows building 'just the right costume' that can yield rapid status gains. In discussing her Harley Quinn costume, 
Kelly said: "I was one of the first people that did it, and this one image of mine kind of went viral. So now people come to me at conventions like 'Oh my god! You're that Harley Quinn! I've seen that!'” Kelly's costume became communally recognized, transforming it into an objectified source of subcultural capital (cf. Thornton 1996) that contributed to her 'cosfame,' an emic term. To put Kelly's communal fame in perspective, she had about 322,000 followers on Facebook at the time of our interview. Other adroit displays of subcultural capital are mash-ups (combining different characters into one costume), gender/race swaps (switching the gender/race of a character), and depictions of rare versions of character aesthetics. Figure 1 provides examples of typical expressions.

Visible effort and attention to detail are hallmarks of a good costume. The ethos of cosplay calls for crafting as much of the outfit as possible. A true cosplayer would never wear a store-bought costume:

Cody: Like as long as it's not a pre-made costume... like you just went out and bought a costume and just put it on. As long as you do it yourself, or like piece together what you made or what you found.

Crafting of the costumes mainly involves "sewing from scratch" (Tina), but can also include pieces from "thrift stores, swap meets, eBay, and flea markets" (Cody). Difficult elements, such as metal or leather parts, are often bought second-hand. Experienced cosplayers aim for perfection and obsess over tiny details to accurately replicate character aesthetics. In discussing his Superman costume, Sam said: "I'm a bit of a perfectionist... Like I made the belt buckle like 6 times [laughs] to get it right because it just wasn't looking right." Material choices and their combinations distinguish novices from seniors. Polly exemplified this: "you really have to understand what's going to look good with silk...or 
using more rough material like this." In a similar vein, Maria remarked that "wigs are one of the things that bother me the most, when they're not very good wigs I'm kind of like [makes a sour face]... getting a real cheap one and having it look bad hurts my soul."

\section{$<<===$ INSERT FIGURE 1 ABOUT HERE $===>>$}

Tools are, of course, essential for making costumes. A sewing machine represents the bare minimum investment for even the most novice cosplayer. Advanced practitioners, however, often acquire specialized tools, such as glue guns, dummy models, or woodworking equipment. Investing in tools and materials as well as learning related skills also contributes to cosplayers developing communal identities around their own "style of cosplaying" (Polly), which usually follows either thematic or craft expertise foci. For instance, Sadie only cosplays Disney's rogue characters, while Carol is known for working mostly with spandex.

In costume performance as cons, the body becomes a central element, especially for experienced practitioners. Cosplay induces body reflexivity and encourages developing a better practice fit (Wacquant 2004). We learned that cosplayers often move from portraying favorite characters to ones that "adhere to their body type" (Tina). For instance, Cody chose to cosplay Captain America because "people sometimes say I look like Chris Evans [the actor portraying Captain America]." Cosplay.com even has dedicated subsections that offer dietary and exercise advice to those looking to shape their bodies for cosplay.

The Ludic Appeal of Costume Crafting. The intrinsic rewards of crafting are central to the emotional appeal of cosplay. Carl, who has made over 50 costumes since the 1970s, described his cosplay engagement in this light: 
Carl: It's another form of art. It's a technical challenge. It keeps your mind active. You learn to figure your way around problems that develop in making a costume. And yeah, it's a release for creativity... My most complex costume is one that I haven't even gotten halfway through yet. It requires electronics that I just haven't mastered yet. But I'm learning. Even at 50 years old, I'm still learning.

Carl's narrative connects to craft activities' ludic and creative side through intrinsically rewarding problem-solving, learning, and flow experiences (Sennett 2008). In addition to play, Carl's experience also reflects the other main characteristics of a fulfilling leisure experience: intrinsic rewards, building mastery, and positive affect (Holbrook and Lehmann 1981; Rojek 2010; Unger and Kernan 1983). We heard frequent stories of losing track of time or being enthralled by costume crafting problems.

Similar to purposefully building of ludic mastery (Huizinga 1949), cosplayers often pursue projects that are slightly beyond their current competence level. New projects enable reflection on previous works and encourage learning. As Jill explained:

Jill (cosplay.com): I've been cosplaying for about a decade now and each time I select a new character I inevitably find a part or some construction method that I've never tried before... The planning of a costume build and the familiarity of materials (glues, fabrics, etc.) becomes much easier with each new cosplay.

For Jill, projects serve as "orchestrating forces" that bind practice materials and meaning to specific competence-building goals (Watson and Shove 2008, 81). Competence is further built through reworking outfits based on experience and feedback: "I alter [costumes] to make them better and fit me again" (Sadie). 
Buying new tools allows for more craft experimentation and project immersion. Tamara recalled a great sense of thrill and a jolt of motivation after buying her glue gun: "It was exciting! It was this feeling of exhilaration... Just trying things over and over again until you get it right and that feeling of getting right, like, 'wow, that's awesome!" Tamara's account illustrates the 'hanging together' of practice elements (Schatzki 1996): novel material elements unlock new forms of competence, which, in turn, facilitate pursuing the practice's desired emotional ends. As Watson and Shove (2008) write, craft consumers' "[practice] competence is embedded in and distributed between tools and materials and many other sources including people, DIY manuals and the internet” (79). Cosplay's online communities are filled with crafting tutorials and discussions related to common problems, aspirations, and novel techniques that members have uncovered. We learned that the vast majority of cosplayers maintain online profiles on platforms such as Facebook, DeviantArt, or cosplay.com. Online profiles allow gaining competence through soliciting feedback for works in progress, and building social capital by interacting with community members.

The inherent ambiguity of crafting is part of cosplay's appeal, as frustration eventually turns into triumph. As Jerry explained, finishing a costume project is greatly rewarding: "the highlight [of crafting] is finishing everything and trying it on and realizing that it actually works... that pays off all the months of hard work or weeks of sewing that people knock out." Rapidly changing communal taste preferences further contribute to the ambiguity of crafting, as peer verdicts are hard to predict. For example, Jacob's satisfaction quickly turned into "feeling bummed" when he saw multiple better-executed versions of what he thought was as an original character choice. This illustrates play's indeterminacy: making a bet with an uncertain payoff (Malaby 2009). That said, crowd appreciation becomes easier to anticipate through experience and by scouting fellow cosplayers' projects online. 
Though crafting is playful and rewarding, taking the finished outfit to con is the highlight of the practice. In the next section, we elaborate on cosplayer's communal play through performing in costume. We begin with the ludic stage itself, the con.

\section{Putting on the Ludic Mask and Going to Con}

The Con Stage. Cons provide spatio-temporally bound stages for play (Huizinga 1949; Kozinets et al. 2004), and represent safe havens for still-stigmatized geek culture consumers (Kozinets 2001). Previous ethnographies have repeatedly described cons as pilgrimage sites, in which stigmatized consumers get to 'geek out' together (Jenkins 2012; Bolling and Smith 2014). In our fieldwork, we heard guests call the con a "homecoming," “our own country," or "a judgment-free zone," indicating themes of liberation, liminality, anti-structure, and communion. The sense of liberation was also evident in con-goers' unrestrained reactions to various con attractions, including cosplayers' costumes.

Cons are held in dozens of North American cities. Bigger cons, such as San Diego Comic-Con, New York Comic-Con, and Wondercon, attract hundreds of thousand of visitors each. These cons have also become central marketing avenues for upcoming geek culture movies, TV shows, or video games (Jenkins 2012; Bolling and Smith 2014). Unlike the reclusive Burning Man and Mountain Man rendezvous' (Belk and Costa 1998; Kozinets 2002), cons are usually held at downtown convention centers. Easy access combined with mainstream interest has recently created ticket shortages, especially at San Diego and New York Comic-Cons.

For cosplayers, cons serve as the central communal get-togethers to interact as well as to gain visibility and feedback for their work. Bigger cons enable more costume interaction and exposure, making them more prestigious for cosplayers. Consequently, the expectations 
for costume quality are higher. However, while most Mountain Men rendezvous' or Burning Man attendees specifically dress up to engage in shared fantasy (Belk and Costa 1998; Kozinets 2002), cosplayers represent a minority of con-goers.

Despite the otherwise playful and geek culture celebrating atmosphere, cons are less than ideal ludic stages for cosplayers (cf. Kozinets et al. 2004). The halls are narrow and crowded, and the con mostly retains the bland look of a convention center. Most of the space is reserved for panel discussions and vendor stalls selling geek culture collectibles. The cons' transformation into more Hollywood-centric events has also undermined organic fan activities, such as cosplay. Luciano lamented San Diego Comic-Con's unenthusiastic cosplay policy:

Luciano: I mean the con doesn’t really do anything to cater for cosplayers, like a photo room or extra stuff at the changing rooms. The con doesn't really care, and they even cut back on [cosplay] panels... It'd be nice if they made more of an effort to keep cosplay alive and a part [of cons]. I think fans think it's important, but I don't think the convention itself does.

Con organizers do promote the presence of cosplayers to attract visitors, but many cosplayers saw this as co-optation rather than true appreciation. Cosplayers thus have to rely on themselves to improve upon their less-than-ideal ludic stages. For instance, cosplayers often volunteer for con organization to ensure cosplay gets featured in event programs.

Smaller cons lacking in celebrity guests feature cosplayers more prominently in event promotion and rely on them more for creating event atmosphere. Larger cons invite famous cosplayers to ensure the presence of high quality costumes and to "participate in costume contests, help run them, help judge them, [do] certain children's events, do trivia contests, 
panel discussions on the hobby" (Rose). In exchange, the invitee usually receives a dedicated booth space in the vendor area: "This [referring to her con booth] turns to be an advertisement also for my work. So like a portfolio that people can see," Carol explained. Becoming an invited cosplayer is a significant mark of status within the cosplay community. Most cosplayers balance costume crafting and con performing, and may thus build only one new costume per year and take it only to select local cons. Some purposefully seek communal fame by taking their outfits to as many cons as possible. Dedicated and famous cosplayers bring separate outfits for each of the con days. Some even hand out business cards or swag that feature links to their online portfolios.

Getting Ready to Play. Performing in costume is an emotional and transformative experience. Putting on the outfit already creates an immediate sense of separation from the everyday self and allows the cosplayer to be "someone else for a day" (Holly). As Ellen explained:

Ellen: It's after you do your make-up, and you get dressed and you put on your wig... it's almost that moment when you catch a glance of yourself in the mirror and you're like oh! I didn't recognize me for a second. I'm someone else right now.

Histories of fandom accentuate these experiences. Mary has been a fan of Janet van Dyne from Marvel comics since she was six. When she put on the finished outfit she recalled crying uncontrollably and exclaiming: "Oh my god, that's Janet! And I brought her to life!"

Costumes quickly reduce social inhibitions: "the number one reason [why I cosplay] is that I'm socially awkward, and cosplay helps with that" (Lee-Ann). Ivy similarly confessed: “In costume I'm not shy at all... I'm very outspoken, I'm very 'I can do whatever 
I want!"” These statements illustrate prototypical ludic elements of using the ludic stage to experiment with social behavior (cf. Belk and Costa 1998). Tatiana chose to portray Lara Croft from the Tomb Raider video game franchise, because the swashbuckling character questions notions of gender and "says f*** you to preconceptions." The outfit also made her feel "more confident and sexy." Beth, a first-time cosplayer, similarly raved about how her outfit of queen Danaerys from the TV-show 'Game of Thrones' gave her extra mojo: "Danaerys is so strong. I feel so much more powerful than I normally would. And that's just wonderful." Being the center of attention is an important aspect of cosplay's appeal, similar to obverse panopticon experiences in ludic servicescapes (Kozinets et al. 2004). Jamaal, cosplaying the titular character from the Quentin Tarantino movie Django Unchained, confessed: “It feels amazing just to walk around and everyone’s like 'Django! Django! The D is silent!' [important catchphrase from the movie] I love it!"

Ludic Character Interaction. Due to the presence of non-cosplayers and less than ideal ludic stage conditions, cosplayers' character play is restrained and intermittent. Cosplayers move back and forth between costume performing, as well as browsing vendor selection and attending panel discussions among other con guests. Performing in costume usually begins when somebody interrupts a wandering cosplayer with a query to pose for a picture. This often attracts others wanting to take a photo. Once the photo-op is over, the cosplayer resumes walking around until the scenario repeats itself. For those with impressive outfits, requests for photos come non-stop. But, as Maria described it: "The constant photo requests are kind of the deal when you wear costumes. You kind of have to expect it."

Competence in costume performing entails learning to mimic the character's signature poses and facial expressions. Here, cosplaying becomes more comparable to modeling than acting or roleplaying; the goal is to wear the costume well. It is play as 
representation, competing over accurate portrayal of valued symbols with other community members (Huizinga 1949). Cosplayers develop this competence by training in front of mirrors or taking test photos to work out posture details with precision. Verbal representation is usually limited to one-off utterances of character catchphrases, yet competent voice acting allows doing this more frequently. One cosplayer dressed as Harley Quinn from Batman comics delighted con guests with her frequent and accurately high-pitched exclamations of “puddin!”-Harley Quinn's term of endearment for her paramour, the Joker. Another cosplayer got eye rolls from passers-by for attempting to channel actor Christian Bale's growling rendition of Batman's voice from Christopher Nolan's movie trilogy. Overtly committed character play thus quickly breaks the illusion of representation (Huizinga 1949). However, cosplayers gladly indulge awe-struck children meeting their favorite characters with prolonged character dialogue. Many count these moments as personal con highlights. Tiffany's (cosplay.com) encounter exemplifies: "I had a girl hug me when I was dressed as Elphaba and she told me 'I think you're pretty Elphaba!' I was glad I was wearing green make up because it actually made me blush."

Cosplayers compensate for the lacking ludic stage by 'playing around' with their characters (cf. Grayson 1999). For example, the amusing contrast of supposed demi-gods dealing with con inconveniences, such as queuing for food or toilets and navigating crowded convention halls, often lent itself to intentionally off-key character play. One cosplayer dressed as Marvel comics' Thor, the Norse god of thunder, drew laughs in the men's room for his indignant commentary on the inferior quality of earth's porcelain urinals compared to the mighty privy craftsmanship on his home realm of Asgard. Trickster characters are particularly conducive to playing around. Marvel comics' character Deadpool, famous for addressing and even mocking the reader directly in comic books, is popular to cosplay precisely due to the free license the character affords. We saw Deadpool cosplayers barge 
into photo-ops uninvited; 'challenge' other characters into duels in intentionally awkward pugilist stances; position weapon props as phallic gestures; spontaneously plunge into exaggerated death scenes; and solicit over-the-top-enthusiastic high-fives from con guests.

Banding together elevates costume performances. Cosplayers form pre-planned or ad hoc groups of thematically consistent characters (e.g., from the same franchise) for group photos or to perform short skits, for example parts of iconic storylines. Outside these group interactions, socializing with fellow cosplayers creates a strong sense of communion (Holt 1995). We saw frequent examples of cosplayers complementing each other's outfits, sharing crafting tips, and exchanging warm hugs. The con thus intensifies ephemeral and dispersed communal links through shared experiences (Arnould and Price 1993).

Cosplay's highly satisfying costuming projects and ludic con performances quickly grip its practitioner and encourage further engagement. Advancing in cosplay prompts attending more cons and pursuing more difficult projects that yield status gains within the cosplay community. However, with deeper engagement comes a growing pressure to continuously develop competence and invest in better materials, which threatens to compromise the emotional ends of the practice. We elaborate on these costs next.

\section{DIFFICULTIES IN MAINTAINING COSPLAY ENGAGEMENT}

\section{Compromised Emotional Ends and Problems with Competence}

The first set of obstacles from increasing cosplay engagement relate to compromised practice meaning. More specifically, time demands, competence plateaus, the loss of playmood, and overt communal competitiveness threaten communal engagement. 
Time Demands. To remain fulfilling, ludic activities necessitate securing time blocks that are mentally and physically devoid of work and family distractions (e.g. Huizinga 1949; Goulding, Shankar, and Elliott 2002; Rojek 2010). The complex problem solving involved in costume crafting makes cosplayers specific about emotional conditions. For example, Selina usually "refuse[s] to work" on cosplay "if I'm not inspired." But as cosplay competences develop and ambitions grow, so do the workload and time demands. Selina noted that the necessity of completing costumes often overrules her mood preferences, which she finds difficult to accept. Consequently, the intrinsic joy of costume crafting is threatened by time crunches and energy exhaustion (cf. Thompson 1996; Cotte, Ratneshwar, and Mick 2004). Time crunch was highly common among cosplayers: "It's sort of rampant in the cosplay scene where everyone talks about how you get a really good idea for a costume, but it's a month out from the con and you end up really crunched for time" (Mandy). As time demands grow, cosplay invariably collides with work and family time considerations, creating “endless stress" (Jenna). Sam routinely struggles with "pulling time together ... you know finding time with life in the way." Falling behind schedule caused Joe (cosplay.com) to sew for " 3 days straight, at least 5 hours each day, sometimes even forgetting to eat and such." Increases in communal social capital can bring additional time demands. For example, Selina's communal recognition induces constant inquiries for crafting tips:

Selina: I get questions all the time. I'm the kind of person that welcomes asking questions. I try to answer them as quickly as I can. I do tutorials online so I get a lot of questions on how to make props... I think it's super important to share that information so that everybody can begin to craft and make their own art. 
Senior community members often feel a moral responsibility to share their knowledge, which helps junior members' learn proper practice performances (see Schau et al. 2009). Selina's narrative clearly evoked this sentiment. However, she later described the frequent queries to feel "like a second job sometimes." Ivy and Lee-Ann, also senior cosplayers, echoed this sentiment in their account of being featured guest cosplayers at cons:

Lee-Ann: I think one of the most common misconceptions about doing this is that you just make costumes and you get invited to go all these cool places. Which is part of it, and it's amazing. But it's very hard work and there's a lot of work to it. And sometimes there's just too many things going on. You have to do normal human things. You need to go to the bank, take care of your pets, do your laundry, take care of the family... So it's not like you go home from the con and you kick your feet up like it was a vacation and you just sleep until the next one. We go home and we work.

Ivy: I'll work on my phone until I fall asleep and it falls on my head.

Lee-Ann: Me too. And it happens every other day.

During our interview, Ivy and Lee-Ann emphasized cosplay being primarily a hobby to them. But, here, cosplay becomes "work." We also see Lee-Ann also contrast her cosplay duties with other practice circuits, such as various family chores. We interpret these "second job" and "work" metaphors to be signs of rising status within the consumption community turning the volitional leisure activity into an obligation, as can happen in serious leisure (Stebbins 1982). This diverges from the findings of previous studies that present rising communal status as primarily rewarding (Schouten and McAlexander 1995). 
Precarious Play-Mood. Cosplayers' play-mood can become compromised in two ways. First, negative interactions irreparably ruin the joyous mood at cons themselves (Huizinga 1949). Second, negative experiences outside of cons induce longer-term reflection on how play is perceived by others, thus compromising motivation to maintain engagement. Interactions with non-cosplaying con guests sometimes lead to tense moments that ruin cosplayers' ludic experiences. In an interview for Vice magazine (Linde 2014), model and cosplay veteran Vivid Vika described her bad con experiences thusly:

Vivid Vika: People would ask for a photo, and "jokingly" grab my butt. Lewd, tactless, raunchy things would be said or asked of me, and followed by a "[joking!]... unless you will." I feel like a lot of people don't realize they are overstepping their grounds, and they don't realize how hurtful, scary, and gross they are being. They see this character that they also know and love and I feel they forget that there is a person inside the costume... Just because I am dressed up, doesn't mean I aim to serve your fantasies... I was cosplaying a video game character, Mad Moxxi from Borderlands 2, who is a very ample busty character. A couple walked by, and the gent was very excited for the character, as he was a big fan of the game. He asked for a photo with me, and right before the camera snapped, I heard his girlfriend saying that he didn't need photos with "some gross slut. I thought you were into real women." I was crushed. It hurt. I didn't do anything. Why am I not "real"? Why am I a slut? I'm character-accurate, and having fun! I think the girlfriend saw my transparent epic sad face. She fumbled a half-assed apology, but I could tell that she said it without even thinking about me, the girl in the suit. 
Vika's account provides multiple instances of a "collapse of the play spirit, a sobering, a disenchantment" (Huizinga 1949, 21). Transgressive play can be fun for everybody involved (Kozinets et al. 2004). Yet such 'joking' and sexually charged transgression are closer to dark play, that is, the purposeful ruining of ludic performances for personal gain or enjoyment (Schechner 1993). Echoing Vika's narrative, we witnessed instances of regular con-goers asking to pose with cosplayers, especially scantly clad ones, and accompanying poses with lewd gestures or placing their hands inappropriately. However, not all such transgressions are intentional. For example, overexcited con-goers, especially younger ones, may 'glomp' cosplayers by giving unsolicited and uncomfortably forceful hugs, which can break costumes. Vika's story also suggests that costumes can depersonalize cosplayers for ludic spectators (cf. Turner and Oakes 1986). We learned that some con guests mistakenly assume that cosplayers are paid performers, which may be a contributing factor.

Extrinsic and intrinsic participation motivations often co-constitute fulfilling ludic experiences (Huizinga 1949; Grayson 1999). However, stark differences in participants' competitive motivations create friction at cons and in the community (cf. Tumbat and Belk 2013). In an effort to seek exposure and expand their portfolios, opportunists, such as aspiring models, actresses, and even porn stars, have begun attending cons in costume. Fame seekers often wear revealing outfits, which many cosplayers see as perpetuating negative stereotypes and undermining cosplay's ethos of fun: "they use and push this as a networking opportunity, which it can be, but at the same time it just throws off a lot of the fun and just the spirit of what this is" (Hank). Overall, there is a growing sense that competitiveness among cosplayers is getting out of hand. Jenny (cosplay.com) lamented: "cosplay has become SOOOO competitive. It's always been but it's even worse now."

Interactions outside of cons can also compromise future cosplay performances, especially for those with higher communal status and recognition. Kelly, whose significant 
Facebook followership we noted earlier, described a moment of realization that her cosplay recognition was no longer merely contained within the cosplay practice circuit:

Kelly: The past two or three years I've started to become recognized, like I was buying jeans at the mall a couple of weeks ago and someone was like 'You're that cosplayer!' and I was like 'Oh no!' I went and hid in the dressing room, like 'No I'm not! I'm not wearing makeup or my hair isn't brushed, go away!'

Though Kelly saw humor in the incident, her story shows how rising status complicates boundaries between leisure and other practices (cf. Thompson and Üstüner 2015). What happens at con does not stay at con. New media in particular create negative post-con experiences. Thornton's (1996) study of club cultures demarcated micro (local online communities) and niche subcultural media (internationally distributed clubbing magazines). Geek culture's niche media - particularly blogs covering superhero movie development often feature impressive cosplay costumes in their con coverage. Niche media exposure carries higher status value than micro media exposure for cosplayers. However, such exposure attracts hostile commentary. Maria recounted comments on her image in a popular niche media blog: “'oh she's just dressing so slutty for attention' and 'oh wow, she shouldn’t be cosplaying that character and she's not the right body type." Cosplay's online communities also fall into negativity, fueled by the growing competitiveness. We saw costume pictures attracting hostile scrutiny and outbursts of jealousy, going as far as cyberbullying. Famous cosplayers are more likely to become targets of negativity. Carol, Ivy, and Lee-Ann all recounted experiencing harassment and sexual advances both at cons and online. Carol's harassment case even required police involvement. 
Adults that 'play too much' are quickly labeled childish and irresponsible (Caillois 1961; Grayson 1999). Cosplay's roots in geek culture further perpetuate this stigma (cf. Kozinets 2001), complicating long-term engagement. Our data includes examples of cosplayers being called "weird," "geeky," "nerdy," or even "insane” and "crazy." Cosplayers thus often fret over the hobby becoming public knowledge at work, similar to derby grrrls (Thompson and Üstüner 2015). The most prominent form of anxiety stems from family members' accusations of cosplay dominating time use and distracting from priorities. For instance, Cindy's family thinks her "free time could be better spent." College students and recent graduates worry that cosplay may threaten their livelihoods:

\footnotetext{
Jaime (cosplay.com): I'm 25 and started cosplay when I was 15. At first I thought I would never give up cosplay... I'm back to working and trying to balance cosplay and everything else. But after this, I'll probably have to go on hiatus while I think about graduate school and trying to find another job after my contract is up next August. I have no idea if I'll come back to it, but I'd feel it would be a total waste if I didn't.
}

Prioritizing cosplay over one's career creates anxiety, and, in Jaime's case, prompted scaling back on ludic consumption involvement, to his great regret. Such anxieties increase with age. For instance, Ian lamented that his family thinks he is "too old and responsible to cosplay."

Competence Plateaus. Cosplay demands constant productivity. Fame garnered from previous costumes fades fast and character trends change rapidly. This creates tension between competitive motivations to build status and the playful meanings of the practice. Many fail at balancing the two, leading to frustrating failures in crafting. Such failures are often connected to materials. For instance, working with new tools or fabrics may produce 
unforeseen failures. Tim (cosplay.com) recounted a traumatic wardrobe malfunction just before a con: "I was so infuriated that I packed up my things and left, tossing the POS costume in the dumpster on my way out, and coincidentally [sic] washing about $\$ 250$ down the drain (hotel room reservation and con registration)." Insufficient time or a lack of routine may similarly compromise projects. Bettie (cosplay.com) laments her lack of preparation in constructing her Elsa costume from Disney's 'Frozen,' resulting in hours of wasted labor and a letdown of personal standards: "I didn't do enough test fits on the dress. In fact, I jumped into sewing sequins on, spent roughly 100 hours sewing them on and horribly regret it... It is soooo not up to par." As many only have the opportunity to go to one or two cons per year, failing to complete an outfit before a con can be a major emotional setback, as it denies the sense of fulfillment and communal con performance appreciation that motivate future projects.

\section{Compounding Material Constraints}

Prolonged cosplay engagement leads to compounding material constraints. Cosplay practices begin intersecting with other practice flows, especially domestic ones, due to cosplay's growing material colonization. Moreover, cosplay brings about mounting material costs that further compromise practice meaning through the challenge of making ends meet.

Material Colonization. Costume crafting is usually confined to pre-determined spaces in the home, such as garages or guest rooms. However, rising ambition necessitates more materials, which leads to space management problems. While cosplayers living alone tolerate the ubiquitous and messy material elements, those with families experience pushback due to cosplay's frequent interruption of domestic practices, indicating a lack of consensus over 
family practices and material relations (Epp and Price 2008). As Jim explained, "[cosplay] consumes your life sometimes... my wife's been very patient with, you know, me messing up the garage and messing up the house." Problems may dissolve once a costume is ready: "the neatness [of my home] is inversely proportional to proximity to con," Michael joked. However, material elements can also permanently colonize home areas and hinder domestic practices. Amy expounded on this: "My boyfriend just shakes his head. He gave up trying to get me to keep my cosplay area under control. He also gave up the hope we'd ever eat at our dining table." Problems flare up especially during fundamental life changes:

Stephanie: Before my fiancé moved in I had lots of floor space in my room, and now it's halved... I need a new wardrobe, mine's full and most of my cosplay stuff is squeezed tightly in between a wall and my wardrobe. The pile is getting bigger there so I'm desperate to get my own space.

Quite naturally, the toxic fumes, loud noises, and sharp objects inherent to costume crafting further limit options for setting up practice materials within domestic settings. These material problems induce guilt that is comparable to earlier depictions of cosplay dominating time use, thereby disturbing the distraction-free mindset needed for crafting.

Making Ends Meet. Cosplay's monetary costs escalate rapidly with growing ambition, leading to the practice's strongest source of anxiety. Moreover, absorption in the practice can reduce awareness of how expenses accumulate over time. Ivy and Lee-Ann recounted being shocked when tallying the costs of their recent projects: 
Ivy: I plugged in how much I'd spent, I was like 'Jesus, I've spent so much money on this thing'... It's obscene, like when you're not paying attention and you're doing it over a certain period like that...You'll be like 'god, this could've been a vacation!'

Lee-Ann: It just blows your mind how much you can spend so quickly. Like five dollars here, ten dollars there. It doesn't seem like a lot, but like over a year it's like 'wow, that's thousands of dollars on a costume that's not even made yet.'

These concerns further intensify when other practice circuits' demands increase. For instance, Carl admitted that the mounting expenses of his daughters' hobbies and education have made him increasingly reflexive and anxious about cosplay projects. This also connects with earlier accounts of cosplayers worrying about being distracted from career goals.

Increasing difficulties can eventually make cosplay engagement altogether unsustainable. Mary (cosplay.com) quit cosplay because she needed "to use my money to support myself rather than on costumes." Becca stopped cosplaying because her job as a nurse crowded out leisure time: "It is hard to get time off work and the hours are very demanding... sure, succeeding in life comes way before a hobby, but it's really hard to give up a hobby which you love and enjoy so much.” However, many find ways around the challenges we have described and stay engaged in cosplay. We illustrate this next.

\section{HOW COSPLAYERS MAINTAIN THEIR COMMUNAL ENGAGEMENTS}

In practice theory, integrated practices are complex and holistic entities involving multiple actions, whereas dispersed practices are simple, yet helpful actions found across many integrated practices (Schatzki 1996). Arsel and Bean (2013) showed dispersed 
practices of problematization, ritualization, and instrumentalization to produce novel taste displays and consequently reshape the integrated practice of home décor. We similarly uncovered three dispersed practices that help sustain cosplayers' communal engagement: modularization, reinforcement, and collaboration.

\section{Modularization: Breaking Down and Rebuilding Practices}

A practice circuit implies a bounded set of conditions through which actions are pursued (Schatzki 2002; Warde 2005). These conditions also denote relations between circuits, including the possibility to create circuit intersections or necessity to separate circuits (Shove et al. 2012). Rojek (2004) wrote that time scarcities promote leisure modularization: favoring hobbies that can be pursued at opportune times over those with rigid schedules. We appropriate the term modularization to describe how cosplayers mitigate crafting pressures by breaking down cosplay practices into modular parts and devising new practice flows that intersect with other circuits or achieve proper separation.

Emphasizing Small Gains and Momentum. An essential part of modularization is breaking large tasks into smaller ones, and propelling the project via small gains. A famous cosplayer described this on her Tumblr page:

Massive cosplay projects can get overwhelming. Many times I'll be half way through a project and realize I've forgotten an important detail or forgotten to make a component of the costume entirely. Other times I'll be getting close to a deadline and become overwhelmed with the work still left to do. I find that the best way to deal with these problems is to keep detailed lists. I usually keep at least one spread sheet 
going that keeps track of what I need to do while working on a project. I will sit down and think about every element of the costume as I study reference photos and break down the costume into parts. I will then list every step that will be needed in order to make each piece... I find that when everything is broken down into small parts nothing seems overwhelming. This also helps with organizing and prioritizing. In the above list I realized that all the weathering and distressing for the costume (highlighted in yellow) could be lumped together and done at the same time. This would save me set up and clean up time when I did it. Having everything laid out on paper also assists with setting up a timetable. When you can see every step that needs doing you can organize it to fit in your schedule. You can fit those 15-minute touchup projects in at the end of a busy workday, or plan on doing 2 hour pattern drafting and mock-up session some time during a free day. This keeps you from neglecting the important aspects of your day-to-day life while still getting progress done on your costume (“Cosplaying-on-a-budget” Tumblr, May 2014)

As the excerpt shows, costume crafting necessitates improvisation, even from experienced practitioners. This can become "overwhelming" and emotionally compromising. Modularization makes the practice's material, emotional, temporal, and labor demands apparent, thus reinstating a sense of agency through synergistic prioritization. For example, "15-minute touchup projects at the end of a busy workday" are tasks that can be performed in less than ideal emotional and temporal conditions. Yet, they free up time for project phases with inflexible, time-consuming practice timeflow structures (Woermann and Rokka 2015), which are left for "free days." Moreover, modularization soothes boundary tensions between practice circuits, as shown by the juxtaposition between "day-to-day life" and cosplay. 
The above excerpt mentions the use of color-coded lists to keep track of project tasks. New technologies often mirror the logic of human labor they complement or displace within practices (Shove et al. 2012). Modularization principles are apparent in a helpful cosplay app that Ivy uses to make sense of her material procurement needs and to manage time use:

Ivy: There's this app called Cosplanner... It literally breaks down everything from your costume. You know, if you need to buy a wig, fabrics, all the different materials, how much they cost... you can also break down all the different component of your costume that you need to make, percentage completed on each one of those... You can realistically see how much it's costing you.

Ivy further notes that the app gives cosplayers enough time to plan material procurement and hunt for bargains. Modularization thus reduces monetary anxiety by making project costs apparent and allowing the search for alternatives. Tim (cosplay.com) explained this benefit:

Tim: My biggest secrets are shopping during sales/with coupons and buying my materials over time. I usually start a project six months before I need it, sometimes less if it's not a real big one. That way, I can still have money for everything else I need, but can make my cosplay.

Saving for a new costume usually begins a few months prior to a con, but some cosplayers begin saving up to "a year in advance from the con's date" (Stan, cosplay.com). Cosplayers use apps like Cosplanner to stay almost ubiquitously engaged with their projects. 
Bundling. Another form of modularization is bundling tasks by identifying actions that can be performed concurrently after they have been broken apart (Shove et al. 2012). Long-time cosplayer Mandy used this approach to complete her outfit in time for a con:

Mandy: Even if you don't feel motivated to physically work on something, try and find work you can do for a different part of that costume or a different costume you might have in mind. So it's like 'oh, I can't really work on sewing, maybe I'll see if I can figure out what the construction of the back could be' and just write that down on paper... If were to watch TV anyway I can work on something that's handwork, I can't work on a [sewing] machine as well, but spending half an hour sewing one of these [shows her costume's embroidery] I can do.

Mandy employs modularization principles by matching project stages with appropriate motivation levels to maintain leisure time's emotional qualities, pursue small gains, and move the project forward. But she also combines the repetitive task of embroidery with TV watching to fuse cosplay with another leisure circuit. Ivy described a similar practice fusion. She lets her favorite TV shows "pile up" on her DVR and catches up on them during crafting. Cosplay practices can also be bundled with work circuits. For instance, hunting for costume source materials fills dead time at work: "When not making rounds [at work]... I do cosplay things to pass time and help stay awake" (Emma, cosplay.com). Moreover, cosplay can become an enjoyable way to simultaneously improve work and leisure competences. A sizable number of cosplayers study or have careers in theater or fashion, creating obvious skill and practice overlaps with cosplay. Sadie, a costume designer for a theater, said her Disney's Little Mermaid costume was motivated both by Disney fandom and a desire "to experiment with building better bustles for work." Slightly tweaking her cosplay practice 
thus helps build work-related competence. Hank expressed a more intricate fusion of work and leisure through approaching cosplay as an "extremely enjoyable way to diversify my portfolio" for his work as a theater costume designer. Sadie and Hank use cosplay to make learning work competence playful (Press and Arnould 2011), soothing the guilt of spending too much time and money on leisure. Fusing leisure and work can even change career aspirations. Garret (cosplay.com) plans "to go back to school and get a college diploma in fashion arts...so I can turn my love of making things into a career.” That said, possibilities for work-leisure fusions become scarce for those with careers beyond aesthetics or crafts.

There are, of course, limits to breaking down a cosplay project and bundling it with other circuits, as Mandy's remark about the sewing machine suggests. Crucial phases necessitate concentration, time, and spatially bound tools. Synergizing work and cosplay practices also has limits, as the combination can erode cosplay enjoyment. For example, Casey, a wardrobe assistant, lamented: "I sew all day at work, so the last thing I want to do when I get home is sew some more." Casey's narrative illustrates that leisure needs to maintain a proper emotional distance from work to remain fulfilling (see Rojek 2010). We also stress that modularization mostly relates to costume crafting. Other than the aforementioned exposure opportunists, we saw scant evidence of committed cosplayers modularizing practices of performing in costume. Maria was an exception as she told us that coming to San Diego Comic-Con also allowed her to "put [herself] out there as an actor."

\section{Reinforcement: Managing Practice Boundaries}

Cosplayers employ organizing principles to reinforce boundaries between leisure and other practice circuits. Reinforcement takes place through moral allocation principles, separating the cosplay practice circuit, tempering competitiveness, and practice advocacy. 
Moral Allocation Principles. Using moral allocation principles for money and time use allows boundary management between leisure and other practice circuits, thereby addressing the problems of making ends meet and of anxiety over time use. Pred (1981) wrote that dominant projects, such as work and family, provide foundational structures to other life practices. Carl reflects this idea: "Family is the most important thing, and the job is what supports the family. [Cosplay] is the recreational part." Carl evokes a typically Western framing of playful leisure being surplus time from work and family practices (Rojek 2010).

Dividing money among practice circuits brings clarity to different regimes of economic capital. Reily (cosplay.com) described her approach: "I divide my paycheck into separate sections: my rent, my school, my spendy money (which normally goes to cosplay)... So I just let it add up.” Once her necessities are covered, additional gains go to the cosplay circuit. Kat (cosplay.com) portrays the 'leisure as surplus' mentality in managing overtime compensation: "I work by hourly so any time I have overtime, I put that money directly into a separate account that is used only for cosplay related purchases. It helps me keep track of exactly how much I spend per costume.”

Cosplayers structure their time use in a similar way. However, because cons are held at fixed times, individuals have less flexibility in time allocations. Securing vacation time between early spring and late fall when big cons are held ('con season') is thus crucial: “I take both Friday and Monday off for a con, so each convention I go to takes 2 days of vacation time. Vacation time gets spent pretty quickly" (Bernard, cosplay.com). Putting in vacation requests in advance creates a moral justification for the requests. For instance, Sam accrues overtime hours to bolster his bargaining position when asking for days off: "I put in enough hours to deserve the time off, so I don't feel guilty using sick days for conventions." 
Separating the Cosplay Practice Circuit. Communal consumers are known to appropriate alternative identities that draw from the context's symbolic lore (Belk and Costa 1998; Kozinets 2002). Cosplay’s ludic masquerading and geek culture lore readily lend themselves to devising alternative identities and personas. These identities create a sense of mystique and artistic prestige around the practice. In online interaction, they also mitigate fears of boundary spillages between leisure and other practice circuits. Hanna explained:

Hanna (cosplay.com): I've taken extra precaution by keeping my cosplay life separate from my real life... I've made a separate Facebook account for cosplay... When being interviewed and your possible future employer asks for your hobbies, just say that you sew things.

In typical ludic fashion, Hanna contrasts the circuits of cosplay and "real life" and expresses a desire to separate cosplay and real-life identities. This is especially important for older consumers with careers. To support persona separation, some cosplayers even choose characters that conceal all facial features to further insulate leisure identities. Separation of identities can also be a security measure. Carol, whose harassment case we noted earlier, meticulously scrubbed all online information linking her cosplay persona and her real name.

Following Goffman (1959), maintaining fulfillment in a stigmatized activity like cosplay necessitates extensive backstage labor on the part of cosplayers to manage front stage audiences and outsiders' exposure to their communal engagement. Artist personas give cosplayers agency over practice performances by channeling status gains into virtual entities, soothing fears of leisure identity spillages. Cosplayers thus often resist the communal practice's identity colonization (cf. Schouten and McAlexander 1995) to maintain its ludic meaning. 
Tempering Competitive Impulses. Status gains are usually seen as an important end in communal engagement (Schouten and McAlexander 1995; Schau et al. 2009). However, our analysis found that fears of jeopardizing long-term practice enjoyment prompted many to routinely ignore attainable status gains. Serena affirmed these fears:

Serena (cosplay.com): I am one of those cosplayers who make their own stuff and won't accept commissions, although I've had dozens of strangers at conventions ask me to. First of all, I have a normal 40-hour-per-week job - actually, career in science that has nothing remotely to do with costuming or cosplay. I costume and cosplay because it is my favorite hobby, and I hesitate to turn my hobbies into second jobs. I work on things when I'm in the mood to, and I know that if I'm not excited about working on a new, unique project, I'll be bored and even the prospect of being paid won't tempt me to get anything done on it. That being said, I do do custom costume pieces for 3-4 select "clients" who are good friends... But commissioning for the general public? Eeeek, no thanks.

Commission requests are a noteworthy acknowledgement of competence and have significant status value within the community. However, Serena rejects opportunities to pursue these gains. As Lastowka (2009) wrote, ludic practices are often kept purposefully inefficient to maintain their contrasting emotional ends vis-à-vis the efficient, bureaucratic, and marketdriven practices of work. For Serena, pursuing status and market opportunities would compromise cosplay's meaning as a ludic release from the rigors of her work life and turn it into 'a second job.' Cosplayers with established communal standing were more likely to resist such opportunities to protect their practice enjoyment. Carol, a sought-after 
commission worker, limits her intake of commission projects, as "[cosplay] is still just something that I love as a hobby." Lee-Ann, also an entrepreneurial cosplayer, described her recent costume as a departure from status chasing in favor of intrinsic joy: "this [costume] is something I did just for me, I really wanted to do it and I loved working on it."

Practice Advocacy. Kozinets (2001) found that Trekkies periodically engaged in charity work at blood drives and charity auctions to legitimize their stigmatized fan activity. We similarly encountered multiple cosplay groups explicitly geared toward charity ventures, most notably, the Star Wars themed $501^{\text {st }}$ legion with 6,000 members worldwide. We also encountered purposeful cosplay advocacy that sought to challenge outsider perceptions of cosplay. The general audience and mainstream media often describe cosplay as childish, escapist, and overtly sexualized. Cosplayers counter these views by emphasizing craft and artistry. In an interview for Nerdbastards.com (2014), Yaya Han, one of the world's most famous cosplayers, explained:

Interviewer: What's one thing that you'd like people to appreciate/understand about cosplay?

Yaya Han: Cosplay is an art form. A unique blend between fan expression and creativity. Many cosplayers create jaw-dropping, professional looking costumes and photos as pure hobbyists. It's the passion and love for the character that drives them. I would like to see more understanding and appreciation for that.

Senior cosplayers we interacted with during our fieldwork displayed similar readiness to challenge perceptions. In con panel discussions that worked as Q\&A sessions for novices, 
Carol, Hank, Lee-Ann, Ivy, and Selina, all took the stage, praising cosplay as a "fulfilling," "healthy," "social," and "creative" hobby for adults and children alike. We also saw multiple discussion threads on cosplay.com giving advise on how to convince parents or friends on cosplay's virtues, as shaping external perceptions would allow for more guilt-free practice engagement. Cosplay perceptions are indeed improving. Carl's cosplay engagement spans four decades and he has witnessed a notable change in general audience reactions: "When I was younger, if you wore a Star Trek uniform to a Star Trek convention, you were totally ostracized. Now, you have in this con alone, 25,000 people. That's acceptance."

Cosplayers, together with organizers, have also taken a more proactive approach to improve upon ludic experiences at cons. Many cons now put up posters stating "Cosplay is not consent" and encourage guests to ask for permission before taking photos and to respect personal space. Cosplay.com members also urged vigilant con harassment interventions.

\section{Collaboration: Joint Projects and Leveraging the Communal Hybrid Economy}

Cosplayers often specialize in craft skills, which can revolve around a type of prop or clothing, such as swords or wigs, or materials and means of production, such as metal work or leatherwear. Specialization benefits both individual cosplayers and the community. Specialized skills grant status to individuals: Carol and Selina both credited their cosfame and frequent inquiries for crafting tips to specific craft competences. At the same time, specialization weaves individual competences and materials into practice networks (Shove et al. 2012) that produce collaboration opportunities in the communal hybrid economy (Scaraboto 2015). 
Networking Practice Elements. Cosplayers recruit fellow cosplayers to improve project outcomes, as Tina testified: "My friend actually helped me. She made the yellow part, the headband, the rest of it I made." Cosplayers also infuse practice circuits with sharing and using other cosplayers' tools and materials. Tamara frequently lends her glue gun to friends, while Violet often uses her friends' accessories: "my friend bought a wig and I can use it." When friends are unable to help, cosplayers turn to the community at large. For instance, cosplayers often use existing tutorials to learn competences, thus mitigating temporal and monetary costs. Tanya often uses tutorials by famous cosplayers, as "a lot of them will show their process [of making costumes] and it's cool to see how they do it... rather than learn everything completely from scratch." Cosplayers also make open calls for help within the community. Our netnographic fieldwork found examples of tool loan and service bartering; queries for car-pooling and hotel room sharing; pre-planning con skits and group photo shoots; organizing pooled material procurements for scale benefits; buying and selling second-hand materials to save on costs. The availability of these communal options influences project planning. Mia noted monetary benefits from communal sourcing:

Mia (cosplay.com): I especially love buying wigs from fellow [cosplay.com] members because a lot of the times they bought it new and didn't like the color or something... you can get high quality things for a really good price"

Mia's story shows that previous ownership and seller descriptions from fellow cosplayers act as social proof of the material's quality, and thus reduce buyers' purchase risk. Sellers benefit by recuperating costs from previous projects and funneling them into future ones: 
As an avid cosplayer, I am always putting together new costumes for cosplaying at conventions. However, this does mean that some of my costumes are older and could use selling. Usually I will hang onto a costume for a few years but after a while, it would be nice to get some of the money back that I spent on the costume in the beginning. This does not mean I have sold all of my costumes - on the contrary, most have sentimental value and represent something I put a lot of work into creating. So the biggest rule of selling a costume on eBay is to be $100 \%$ positive you won't regret losing it. (Excerpt from "cosplay selling guide" on eBay.com)

All materials don't enjoy equal liquidity within the communal market. Wigs and props are in high demand, but used costumes less so in a community that grants status from craft acumen. Costumes are thus taken to non-communal marketplaces like eBay to maximize returns. Personally meaningful items are considered off limits for economic capital conversion, as the excerpt above illustrates. Marcelo (cosplay.com) echoes this sentiment: "I only sell a costume when I know I'm not going to wear it again, otherwise you could be wasting on money opportunities.”

Cosplay's emphasis on novelty creates a short shelf life for costumes and encourages constant productivity, which benefits the active second hand market. Moreover, selling unneeded materials solves problems relating to cosplay materials' colonizing presence at home. Channeling recuperated costs into new projects also links back to the moral allocation principles described earlier.

Those with time constraints or insufficient crafting skills often opt to commissioning a full costume from the communal market. Rob explained this approach: "If it's something you know you will have trouble doing, and will go through expensive trial and error in making, it's best to commission." For the one taking on the job, commission work provides 
an avenue for building status (costumers are expected to credited) and a secondary income: "the ones that [commission] as a mix of hobby and side money actually make some pretty decent cash for basically just putzing around with art and craft supplies while they watch TV" (Helen, cosplay.com). Cosplayers tend to keep the commission money they make within the cosplay practice circuit, affirming the moral allocation principle once again. Clark (cosplay.com) recounted: "in order to go to more than just two cons a year, I get artist alley tables and sell my [cosplay] wares. I make back my expenses in a day or two, it's a win-win." For Karen, commissioning is central for maintaining her cosplay engagement:

Karen (cosplay.com): I'm trained as a teacher, but due to some crazy allergies that popped up while off having a baby, I won't be able to go back to that. Cosplay taught me that I'm REALLY good at sewing, and that I love it. I'll be using my sewing skills to make money for the rest of my life, most likely. Is it annoying sometimes? You bet. But it's something I'm good at and it doesn't require me to put my kids in daycare... As long as I can make enough money to pay for my own cosplay supplies, some private lessons for the kids, and our vacation fund, I'll be satisfied.

Karen's conversion of her cosplay-related competence to economic capital has become central to supporting her cosplay engagement as well as her family practices. However, extensive commissioning may introduce ambivalence to ludic sensations, as exemplified by Karen sometimes finding her favorite hobby annoying.

Collaborative Status Gains. Commissioning lends itself to collaborative status building arrangements that are commonly motivated by crafting difficulties. Cosplayers commission key components from more skilled craftsmen. Maria described her arrangement: 
Maria: I actually commission because I am terrible at actual construction but I work with the people that I commission very closely... That's how I managed to get my badge [to San Diego Comic-Con], because the costume maker, she got a professional badge and she allowed me to go because I'm a representation of her work. I mean that's her business. Her business is making costumes. I definitely tell people, I give credit where credit is due... I'm more of an idea maker than an actual builder. I just recognize that I can't sew, and I can't really build things really well. And if I try, it won't come out as well, it will take more time and more energy and more resources than if I just had somebody who knew what they were doing do it in the first place. So, it gives them business and connects me with some really cool people and it allows me to not get frustrated and waste a bunch of time and money.

Maria purposefully pursues recognition as a performer, as shown by her earlier assertion that she was the first to cosplay certain characters in the US con circuit. She acknowledges that her crafting competence has plateaued, which conflicts with her ambition. She fears pushing through the plateau would further compromise her cosplay enjoyment and waste resources. Maria and the commission builder mutually benefit from their arrangement: Maria debuts a new outfit for communal attention, and the costumer gains recognition for her crafting competence. While status gains drive the arrangement, Maria's account shows a desire to avoid compromised emotional ends. Given cosplay's emphasis on craft, those who commission are expected to participate in the process. Maria was sure to note that she influenced the project with her own ideas while still giving full credit to the costumer.

Communal social capital facilitates finding mutually advantageous collaboration opportunities (Arsel and Thompson 2011). For example, Roxanne was one of the few 
cosplayers we encountered who openly embraces the title of professional cosplayer. She revealed that some of the recent outfits she wore were given to her by aspiring costumebuilders in hopes of exposure, an arrangement she described as mentorship.

\section{DISCUSSION}

Previous research has found communal consumption highly conducive to ludic experiences and its related sensations of anti-structural communion, social bonding, and fun (e.g., Arnould and Price 1993; Celsi et al. 1993; Holt 1995; Schouten and McAlexander 1995; Belk and Costa 1998; Kozinets 2002). However, the orchestration of ludic consumption experiences has been seen as the purview of marketers (Tumbat and Belk 2013; see Arnould and Price 1993; Sherry 1998; Kozinets et al. 2004), while consumers' own facilitation and potential difficulties in doing so have been ignored. Our ethnographic inquiry of cosplay provided a detailed account of how consumers produce and maintain ludic communal experiences in a servicescape where marketers provided limited facilitation.

Prototypical descriptions of play define it as a free, social, unproductive, and voluntary activity done for its 'own sake' and to achieve a leisurely escape from everyday concerns (Huizinga 1949; Caillois 1961; Grayson 1999). These elements were undeniably apparent in many cosplayers' stories; cosplay revealed itself to be an emotionally rewarding ludic activity that combines intrinsically pleasurable costume crafting with joyous communal masquerading. However, cosplayers' ludic experiences were intermittent, irregular, and never guaranteed. More importantly, they were the result of hard work and entailed tradeoffs between various ludic ends. Our findings thus depart from previous studies that presented ludic experiences as inherent, ubiquitous, and even inevitable outcomes of communal consumption (Arnould and Price 1993; Belk and Costa 1998; Kozinets 2002). 
The tradeoffs and threats to ludic experiences compounded as communal engagement in cosplay deepened. In exploring these, we clarified the role of various instrumental costs to communal consumption, which have received little attention in previous research (Celsi et al. 1993; Schouten and McAlexander 1995). Belk and Costa’s (1998) study of Mountain Man rendezvous provides an appropriate comparison study, given the contextual similarities. Just like cosplayers, mountain men value homemade costumes and ludic performances at their respective 'cons,' the rendezvous. Belk and Costa briefly note the growing material and temporal demands of communal engagement, but treat them largely as inevitable or nominal consequences. In our context, mounting instrumental costs compromised ludic experiences in the short term and threatened engagement in the long term. For example, costume crafting was central to cosplay's ludic appeal, but frequently led to time crunches, frustrating failures, and various tensions in domestic settings and even fear of stigmatization that further complicated finding the right play-mood. Similarly, status and peer recognition are considered inherent to the appeal of both play and communal consumption (Huizinga 1949; Schouten and McAlexander 1995; Belk and Costa 1998; Schau et al 2009). Yet in our context status gains could compromise ludic enjoyment by introducing additional communal duties, threatening leisure volition, and attracting hostile communal commentary.

Mounting instrumental costs even caused some to abandon cosplay altogether. This allowed us to provide a novel perspective on why consumers leave consumption communities. Previous works have identified inevitable life transitions (Thornton 1996; Goulding et al. 2002), the loss of consumption practices' identity value (Arsel and Thompson 2011; McAlexander et al. 2014), and negative shifts in communal dynamics (Muñiz and Schau 2005; Parmentier and Fischer 2015) as primary reasons for leaving. Though elements of all three explanations were evident in cosplayers' stories, we believe the decisions to move away from cosplay were primarily caused by pervasive practice misalignments that the 
instrumental costs produced. In other words, ludic experiences were becoming more and more unattainable. Our findings answer the call made by Woermann and Rokka (2015), who urged researchers to pay more attention to the consequences of practice alignment and misalignment, as they saw these dynamics to be integral to understanding how consumption practices remain attractive to consumers.

To regain their ludic sensations and maintain communal engagements, cosplayers utilized a set of dispersed practices we called modularization, reinforcement, and collaboration. Again, these responses entailed tradeoffs between various ludic ends. Modularization meant compromising leisure's important spatio-temporal separation with work and family practices to maintain project momentum. Reinforcement entailed not pursuing clearly attainable status gains and skill recognition to maintain play volition and leisure separation. Collaboration introduced entrepreneurial market rationality - anathema to prototypical ludic experiences (Huizinga 1949; Caillois 1961) - into the practice to protect its long-term viability. The three responses extend previous findings on how consumers shape their practice flows to improve upon their outcomes. For example, Arsel and Thompson (2011) showed indie enclaves insulating consumption practices to shield their identities from unflattering hipster associations, similar to our reinforcement response (see also Kozinets 2001). Our findings on collaboration practices complement studies that have presented the seeking of help within a community mostly as a form of soliciting emotional peer support or as proactive practice learning (Schau et al. 2009; Coskuner-Balli and Thompson 2013). Previous research has privileged the role of subcultural and social capital stocks in practice advancement (Schouten and McAlexander 1995; Kates 2002; Schau et al. 2009), yet modularization, reinforcement, and collaboration de-emphasize the role of these capitals in practice advancement, opening up new pursuits within the community. 
The three forms of maintaining communal engagement reaffirm the importance of a practice's teleoaffective structure (Schatzki 1996) or meaning (Shove et al. 2012) in driving practice realignment by determining "what constitutes a problem and for what reasons this problem needs to be resolved" (Arsel and Bean 2013, 913). Here, we concur with Thompson and Üstüner (2015), who note that previous studies tend to overtly detach consumers' volitional communal consumption experiences from other practice circuits, in their case gender role scripts at work and at home. While our analysis was not grounded in sociological circumstances like Thompson and Üstüner's (2015) study was, cosplayers' mounting instrumental costs were often inherently linked to domestic practices and boundary issues between leisure and other practice circuits. Solving these problems further required crosscircuit considerations.

The frequent tradeoffs between ludic elements in our study reintroduce concerns over play's conceptual murkiness (Grayson 1999). If practically all of its defining elements can be compromised to some degree, what, in the end, is play? Here, we agree with Malaby's (2009) assertion that contemporary ludic experiences, which he sees as diverging from Huizinga's (1949) and Caillois' (1961) idealized depictions, are best defined through a disposition towards the indeterminate: "play becomes an attitude characterized by a readiness to improvise in the face of an ever-changing world that admits of no transcendently ordered account" (206). Despite all the compromises, cosplayers ultimately cherished a sense of expectation and discovery within their practice. For example, for senior cosplayers the practice had become more serious and rationalized than for novices, yet their experiences retained important elements of surprise and improvisation.

Our findings also bring new insights to value theorizations. We extend Schau et al.'s (2009) work, in which they described how continuous learning of community practices expands members' consumption opportunities with their favorite brands, thus increasing their 
use and symbolic value. We have shown that modularization and reinforcement give consumers control over costs and allowe them to seek better value through bargain hunting. Collaboration has even more profound value implications, as joint projects give members the opportunity to sell their production to recuperate costs or to pursue time and material savings. These gains could, in turn, be invested into new projects within the communal practice circuit. Collaboration also reduces costs and risks through the availability of second hand materials that have been 'vetted and reviewed' by knowledgeable consumers.

Our study also provides new insights to communal hybrid economies and particularly how moral relations between exchange forms, such as gift-giving and selling, are negotiated (Scaraboto 2015). Cosplay's status logic emphasized self-crafting as much as possible. However, cosplayers have a shared understanding that costume projects are pursued amidst pressures of supporting families and with mounting material costs. Awareness of these shared struggles greatly influenced the moral structuring of communal exchange forms. For example, selling production 'out' from the community was permitted in cosplay, which runs counter to typical findings from communal or subcultural economies (cf. Thornton 1996; Kozinets 2002). Though it conflicts with cosplay's craft ethos, cosplayers were also highly understanding of costume commissioning. Therefore, communally shared practice struggles influence the negotiation of commoditization principles, that is, what types of communal production can be bought or sold, and by whom (Schau et al. 2009).

Martin and Schouten (2014) similarly found permissiveness to monetization in the context of Minimoto. We propose that this permissiveness was influenced by similar shared concerns regarding the practice's and the community's long-term viability. Martin and Schouten (2014) briefly note that building Minimotos entails tradeoffs between adrenalinefilled fun and family safety concerns. Our findings suggest that maintaining specific emotional ends of a practice is central to the process of consumer-driven market emergence. 
Our last contribution provides new insights into the role of social media in consumption community engagement. As noted earlier, previous studies have portrayed gaining communal recognition and building social capital as ways of increasing consumption enjoyment and opportunities (Schouten and McAlexander 1995; Belk and Costa 1998; Kates 2002). This may still hold true to geographically bound or small face-to-face communities, yet largely online-based communities with thousands of people merit alternative interpretations. McQuarrie et al. (2013) found that rising status and growing communal audiences changed fashion bloggers' expressions from personal to more 'detached,' and their professional taste displays to a more carefully cultivated blogger persona. They described this as a process maturation that follows cultural capital accrual. We wish to offer an alternative explanation. Similar to fashion bloggers, cosplayers cultivated communal followings in the hundreds of thousands, which lead to detachment and persona cultivation. However, we attributed these responses to growing concerns over high visibility and ensuing emotional and identity-related consequences. Cosplayers thus used these cultivated personas to feel safe and in control of their communal engagements.

\section{Limitations and Future Research}

Our research was conducted in various North American cities and in the specific context of pop culture conventions with relatively young and mostly college-educated consumers. Findings may therefore vary across national and especially subcultural contexts. We limited our study's focus to the instrumental costs hampering ludic consumption experiences. We feel that expanding on the notion of engagement costs and subsequent consumer responses is a high priority for future research. We also believe that such a project 
would benefit from more sociologically grounded approaches, for example a comparison of how HCC and LCC populations' responses differ (cf. Holt 1997).

While our study found implications for value research, we did not specifically mobilize value as a key concept in our research. We believe that difficulties in maintaining communal engagement combined with value analyses may provide avenues for future research. On a related note, we conceptualized modularization, reinforcement, and collaboration as dispersed practices likely to be found in other contexts, similar to Arsel and Bean (2013). As considerations of practice boundaries were central to all of these, we believe that our findings may also have great impact on the study of how consumption fields or practices evolve through consumers' practice innovations. We further believe our study provides new directions for studying consumer entrepreneurship. Most of our informants did not pursue entrepreneurship, but did take up opportunities that arose in the community, at the same time restraining their impulses to professionalize their hobby due to fears of losing practice enjoyment. Fully unpacking this dynamic would be of great benefit to research.

\section{REFERENCES}

Arnold, Stephen J., and Eileen Fischer (1994), "Hermeneutics and Consumer Research," Journal of Consumer Research, 21 (1), 55-70.

Arnould, Eric J. and Linda L. Price (1993), "River Magic: Extraordinary Experience and the Extended Service Encounter," Journal of Consumer Research, 20 (1), 24-45.

Arnould, Eric J., and Linda L. Price (2000), “Authenticating Acts and Authoritative Performances," in The Why of Consumption: Contemporary Perspectives on Consumers' Motives, Goals, and Desires, ed. S. Ratneshwar, David Glen Mick, and Cynthia Huffman, New York: Routledge, 144-63. 
Arnould, Eric J. and Craig J. Thompson (2005), “Consumer culture theory (CCT): Twenty years of research," Journal of Consumer Research, 31(March), 868-82.

Arnould, Eric J., and Melanie Wallendorf (1994), "Market-Oriented Ethnography: Interpretation Building and Marketing Strategy Formulation.” Journal of Marketing Research, 21 (November), 484-504.

Arsel, Zeynep, and Jonathan Bean (2013), "Taste Regimes and Market-Mediated Practice," Journal of Consumer Research, 39 (February), 899-917.

Arsel, Zeynep and Craig J. Thompson (2011), "Demythologizing Consumption Practices: How Consumers Protect Their Field-Dependent Identity Investments from Devaluing Marketplace Myths," Journal of Consumer Research, 37 (5), 791-806.

Belk, Russell W., and Janeen Arnold Costa (1998), “The Mountain Man Myth: A Contemporary Consuming Fantasy," Journal of Consumer Research, 25 (December), $218-40$.

Bolling, Ben, and Matthew J. Smith (2014), It Happens at Comic-Con: Ethnographic Essays on a Pop Culture Phenomenon, Jefferson, NC: McFarland.

Caillois, Roger (1961), Man, Play, and Games, Glencoe, IL: University of Illinois Press.

Celsi, Richard L., Rose, Randy L. and Leigh, Thomas W. (1993), An Exploration of HighRisk Leisure Consumption through Skydiving. Journal of Consumer Research, 20 (June), 1-23.

Coskuner-Balli, Gokcen, and Craig J. Thompson (2013), “The Status Costs of Subordinate Cultural Capital: At-Home Fathers' Collective Pursuit of Cultural Legitimacy through Capitalizing Consumption Practices," Journal of Consumer Research, 40 (June), 19-41. Cosplay.com forums, http://www.cosplay.com/ 
Cotte, June, S. Ratneshwar, and David Glen Mick (2004), “The Times of Their Lives: Phenomenological and Metaphorical Characteristics of Consumer Timestyles," Journal of Consumer Research, 31 (September), 333-45.

Epp, Amber M., and Linda L. Price (2008), "Family Identity: A Framework of Identity Interplay in Consumption Practices," Journal of Consumer Research, 35 (1), 50-70.

Goffman, Erving (1959), The presentation of self in everyday life, New York, NY: Doubleday.

Goulding, Christina, Avi Shankar, and Richard Elliott (2002), "Working Weeks, Rave Weekends: Identity Fragmentation and the Emergence of New Communities,” Consumption, Markets and Culture, 5 (4), 261-84.

Grayson, Kent (1999), “The dangers and opportunities of playful consumption," in Consumer value: A framework for analysis and research, ed. Morris B. Holbrook, Psychology Press, London: Routledge, 105-126.

Gunnels, Jen (2009), “A Jedi like my father before me”: Social identity and the New York Comic Con, Transformative Works and Cultures, 3 (3), DOI: 10.3983/twc.2009.0161 Hassler-Forest, Dan (2012), Capitalist Superheroes: Caped Crusaders in the Neoliberal Age, Winchester, UK: Zero Books.

Holbrook, Morris B. and Elizabeth C. Hirschman (1982), “The Existential Aspects of Consumption: Consumer Fantasies, Feelings, and Fun," Journal of Consumer Research, $9(2), 132-140$.

Holbrook, Morris B., and Donald R. Lehmann (1981), “Allocating Discretionary Time: Complementarity among Activities," Journal of Consumer Research, 7 (4), 395-406.

Holbrook, Morris B., Robert W. Chestnut, Terence A. Oliva, Eric A. Greenleaf (1984), "Play as a consumption experience: The roles of emotions, performance, and personality in the enjoyment of games," Journal of consumer research, 11(2), 728-739. 
Holt, Douglas B. (1995), "How consumers consume: A typology of consumption practices," Journal of Consumer Research, 22 (1), 1-16.

Holt, Douglas B. (1997), "Poststructuralist Lifestyle Analysis: Conceptualizing the Social Patterning of Consumption in Postmodernity," Journal of Consumer Research, 23 (4), 326-50.

Huizinga, Johan (1949), Homo Ludens. A Study of the Play-Element in Culture, London, UK: Routledge and Kegan Paul Ltd.

Jenkins, Henry (2012), “Superpowered Fans: The Many Worlds of San Diego’s Comic-Con,” Boom: A Journal of California, 2 (2), 22-36.

Kates, Steven M. (2002), “The Protean Quality of Subcultural Consumption: An Ethnographic Account of Gay Consumers," Journal of Consumer Research, 29 (December), 383-399.

Kozinets, Robert V. (2001), “Utopian Enterprise: Articulating the Meanings of Star Trek’s Culture of Consumption," Journal of Consumer Research, 28 (June), 67-88. (2002), "Can Consumers Escape the Market? Emancipatory

Illuminations from Burning Man,” Journal of Consumer Research, 29 (1), 20-38. (2010), Netnography: Doing Ethnographic Research Online. London,

UK: Sage.

Kozinets, Robert V., John F. Sherry Jr., Diana Storm, Adam Duhache, Krittinee Nuttavuthisit, and Benet DeBerry-Spence (2004), "Ludic Agency and Retail Spectacle," Journal of Consumer Research, 31(3), 658-672.

Lastowka, Greg (2009), "Rules of Play," Games and Culture, 4(4), 379-395.

Linde, Jess (2014), "Cosplay Is Not Consent: Exploring the Dark Side of Adult Dress-Up," Vice, Accessed at: http://www.vice.com/read/cosplay-is-not-consent 
Maclaran, Pauline and Stephen Brown (2005), “The Center Cannot Hold: Consuming the Utopian Marketplace," Journal of Consumer Research, 32 (2), 311- 323.

Malaby, Thomas M. (2009), “Anthropology and play: The contours of playful experience,” New Literary History 40 (1), 205-218.

Martin, Diane M., and John W. Schouten (2014), “Consumption-Driven Market Emergence," Journal of Consumer Research, 40 (5), 855-70.

McAlexander, James H., Beth Leavenworth DuFault, Diane M. Martin, and John W. Schouten (2014), “The Marketization of Religion: Field, Capital, and Consumer Identity," Journal of Consumer Research, 41 (3), 858-75.

McQuarrie, Edward F., Jessica Miller, and Barbara J. Phillips (2013), “The Megaphone Effect: Taste and Audience in Fashion Blogging," Journal of Consumer Research, 40 (1), 136-58.

Miles, Matthew B., and A. Michael Huberman (1994), Qualitative Data Analysis: An Expanded Sourcebook, 2nd edition, Thousand Oaks, CA: Sage.

Muñiz, Albert M., and Hope Jensen Schau (2005), "Religiosity in the abandoned Apple Newton brand community," Journal of Consumer Research, 31 (4), 737-747.

Nerdbastards.com (2014) “INTERVIEW: Yaya Han Talks Drama, Sexuality, And How We're All In This Together," Accessed at http://nerdbastards.com/2014/05/27/interview-yaya-han-talks-drama-sexuality-and-howwere-all-in-this-together/

Otnes, Cele C., Behice Ece Ilhan, and Atul Kulkarni (2012), “The language of marketplace rituals: implications for customer experience management," Journal of Retailing, 88 (3), $367-383$

Parmentier, Marie-Agnes and Eileen Fischer (2015), “Things Fall Apart: The Dynamics of Brand Audience Dissipation,” Journal of Consumer Research, 41(5), 1228-1251. 
Pred, Allan (1981), "Social Reproduction and the Time-Geography of Everyday Life," Geografiska Annaler. Series B, Human Geography, 63 (1), 5-22.

Press, Melea, and Eric J. Arnould (2011), "How Does Organizational Identification Form? A Consumer Behavior Perspective," Journal of Consumer Research, 38 (4), 650-66. Ritzer, George (1999), Enchanting a Disenchanted World: Revolutionizing the Means of Consumption, Thousand Oaks, CA: Pine Oaks/Sage.

Rojek, Chris (1995), Decentering Leisure: Rethinking Leisure Theory, London, UK: Sage. (2004), "Postmodern Work and Leisure," in Work and Leisure, ed. John T.

Haworth and A.J. Veal, London, UK: Routledge, 51-66. (2010), The Labour of Leisure: The Culture of Free Time, London, UK: Sage.

Saler, Michael (2012), As If: Modern Enchantment and the Literary Prehistory of Virtual Reality, Oxford, UK: Oxford University Press.

Scaraboto, Daiane (2015), “Selling, Sharing, and Everything In Between: The Hybrid Economies of Collaborative Networks," Journal of Consumer Research, 42 (1): 152-76. Schatzki, Theodore R. (1996), "Practices and Actions: A Wittgensteinian Critique of Bourdieu and Giddens," Philosophy of the Social Sciences, 27 (3), 283-308. (2002), The Site of the Social: A Philosophical Account of the

Constitution of Social Life and Change, University Park: Pennsylvania State University Press.

Schau, Hope J., Albert M. Muñiz Jr. and Eric J. Arnould (2009), “How Brand Community Practices Create Value," Journal of Marketing, 73 (5), 30-51.

Schechner, Richard (1988 [1977]), Performance Theory, Second edition of Essays on Performance Theory, New York, NY: Routledge. (1993), The Future of Ritual: Writings on Culture and Performance, New York, NY: Routledge. 
Schouten, John W., and James H. McAlexander (1995), "Subcultures of Consumption: An Ethnography of the New Bikers," Journal of Consumer Research, 22 (June), 43-61. Scott, Suzanne (2013), "Fangirls in Refrigerators: The Politics of (in)visibility in Comic Book Culture," Transformative Works and Cultures 13, DOI: 10.3983/twc.2013.0460. Sennett, Richard (2008), The Craftsman, New Haven: Yale University Press.

Seregina, Anastasia (2014), "Exploring Fantasy in Consumer Experiences," in Consumer

Culture Theory (Research in Consumer Behavior, Volume 16), ed. John W. Schouten, Diane M. Martin, and Russell W. Belk, London, UK: Emerald Group Publishing Limited, 19-33.

Sherry, John F. (1998), Servicescapes: The Concept of Place in Contemporary Markets, Chicago, IL: NTC Business Books.

Shove, Elizabeth, Mika Pantzar, and Matt Watson (2012), The Dynamics of Social Practice: Everyday Life and How It Changes, London, UK: Sage.

Spiggle, Susan (1994), “Analysis and Interpretation of Qualitative Data in Consumer Research," Journal of Consumer Research, 21 (3), 491-503.

Stebbins, Richard (1982), "Serious Leisure: A Conceptual Statement,” The Pacific Sociological Review, 25 (2), 251-72.

Thompson, Craig J. (1996), “Caring Consumer: Gendered Consumption Meanings and the Juggling Lifestyle," Journal of Consumer Research, 22 (March), 388-407.

Thompson, Craig J. and Üstüner, Tuba (2015), "Women Skating on the Edge: Marketplace Performances as Ideological Edgework," Journal of Consumer Research, 42(2), 235-65. Thornton, Sarah (1996) Club Cultures: Music, Media, and Subcultural Capital, Hanover, NH: University Press of New England.

Tumbat, Gülnür and Russell W. Belk (2011), "Marketplace Tensions in Extraordinary Experiences," Journal of Consumer Research, 38 (1), 42-61. 
(2013), “Co-construction and performancescapes," Journal of Consumer

Behavior, 12, 49-59.

Turner, Victor (1982), From Ritual to Theatre: The Human Seriousness of Play, London,:

PAJ Publications.

Turner, John C., and Penelope J. Oakes (1986), “The significance of the social identity concept for social psychology with reference to individualism, interactionism and social influence," British Journal of Social Psychology, 25 (3), 237-252.

Unger, Lynette S., and Jerome B. Kernan (1983), “On the Meaning of Leisure: An Investigation of Some Determinants of the Subjective Experience, ” Journal of Consumer Research, 9(4), 381-92.

Wacquant, Loïc J.D. (2004), Body and Soul, Oxford, New York: Oxford University Press.

Warde, Alan (2004), "Consumption and Theories of Practice," Journal of Consumer Culture, $5(2), 131-53$.

Watson, Matthew and Elizabeth Shove (2008), "Product, Competence, Project and Practice: DIY and the dynamics of craft consumption," Journal of Consumer Culture, 8 (1), 69 89.

Winge, Theresa (2006), “Costuming the Imagination: Origins of Anime and Manga Cosplay," Mechademia, 1 (1), 65-76.

Woermann, Niklas and Joonas Rokka (2015), “Timeflow: How Consumption Practices Shape Consumers' Temporal Experiences," Journal of Consumer Research, 41 (6), 14861508. 


\section{FIGURE 1}

\section{COSPLAY COSTUMES AND CON PERFORMANCES}

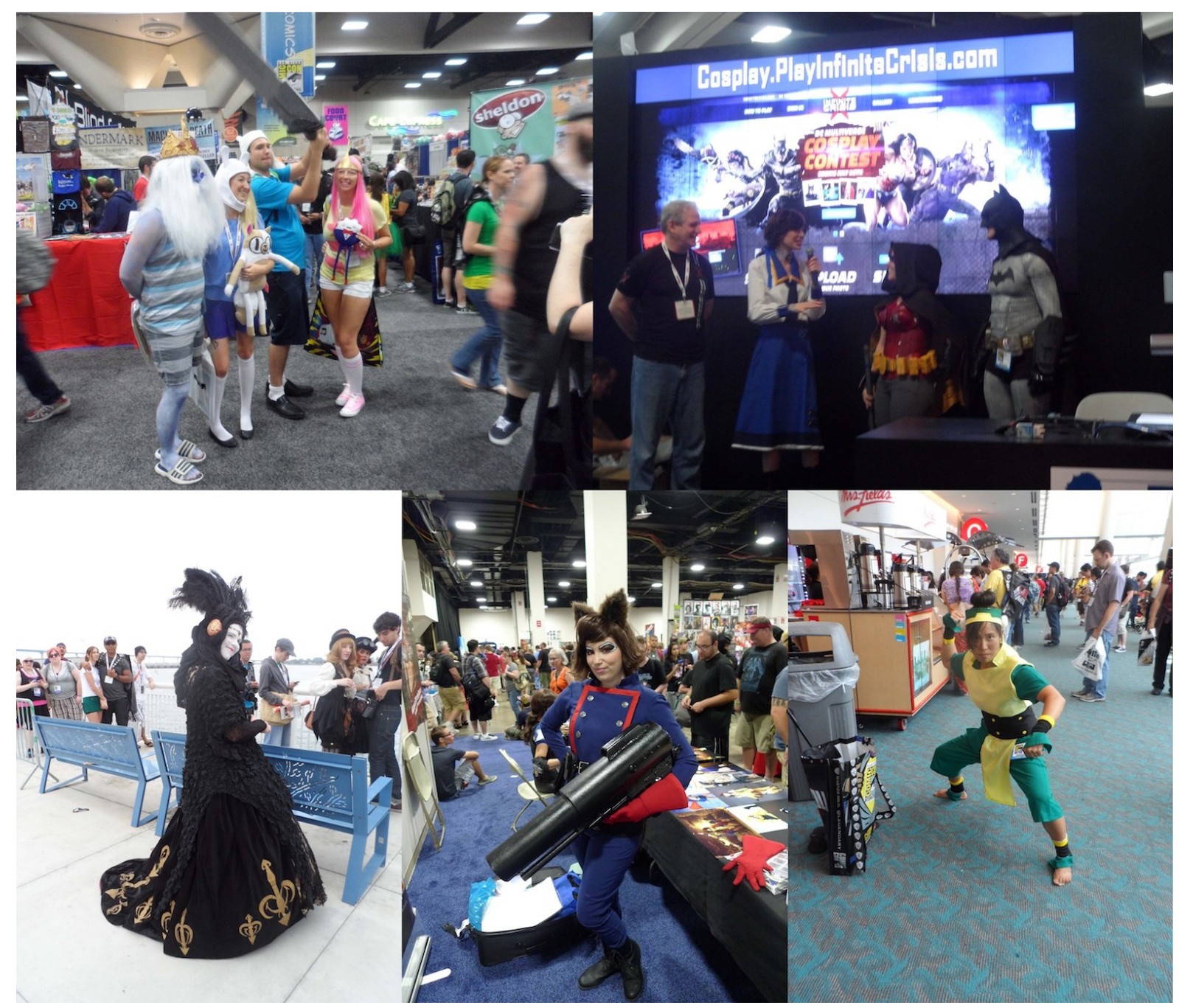

NOTE. - First row: Cosplayers posing for ad hoc group photo (left); cosplayers

performing in costume contest (right). Second row: Costume with elaborate detail and high levels of accuracy (left); invited guest cosplayer posing in front of her con booth (middle); cosplayer assuming character's signature pose (right). 
TABLE 1

RESEARCH DATA SOURCES

\begin{tabular}{|c|c|c|c|}
\hline Name & Sources & Dataset & Purpose \\
\hline $\begin{array}{l}\text { Ethnographic } \\
\text { notes }\end{array}$ & $\begin{array}{l}\text { Notes from fieldwork at } \\
\text { conventions: San Diego Comic- } \\
\text { Con 2013, Rhode Island Comic- } \\
\text { Con 2014, Boston Comic-Con } \\
\text { 2014, 2015, 2016, Anime Con } \\
\text { Boston 2015, 2016. }\end{array}$ & $\begin{array}{l}53 \text { double- } \\
\text { spaced pages }\end{array}$ & $\begin{array}{l}\text { Gaining understanding of } \\
\text { context, and especially of } \\
\text { conventions, as leisure } \\
\text { locations and materiality. } \\
\text { Organized cosplay activities. }\end{array}$ \\
\hline Photography & Photography during fieldwork & $\begin{array}{l}908 \\
\text { photographs }\end{array}$ & $\begin{array}{l}\text { Elaborating the intricacies of } \\
\text { costume crafting and taste } \\
\text { structures based on aesthetic } \\
\text { merit. }\end{array}$ \\
\hline $\begin{array}{l}\text { Recorded } \\
\text { interviews }\end{array}$ & $\begin{array}{l}\text { Cosplayers at conventions. } \\
\text { Interviews ranged from 5-90 } \\
\text { min (average length } 20 \mathrm{~min} \text { ). }\end{array}$ & $\begin{array}{l}64 \text { interviews, } \\
312 \text { double- } \\
\text { spaced pages }\end{array}$ & $\begin{array}{l}\text { Understanding the process of } \\
\text { and emotional engagement in } \\
\text { costume crafting, including } \\
\text { difficulties and sense of } \\
\text { achievement. }\end{array}$ \\
\hline $\begin{array}{l}\text { Netnography } \\
\text { in online } \\
\text { community }\end{array}$ & Cosplay.com archives & $\begin{array}{l}145 \text { discussion } \\
\text { threads, } 4278 \\
\text { double-spaced } \\
\text { pages }\end{array}$ & $\begin{array}{l}\text { Deeper study of themes } \\
\text { through key words emically } \\
\text { identified, particularly in } \\
\text { negative cases; boundary } \\
\text { conditions, sensitive topics } \\
\text { and anxieties often } \\
\text { undisclosed in interviews. }\end{array}$ \\
\hline $\begin{array}{l}\text { Other } \\
\text { netnography }\end{array}$ & $\begin{array}{l}\text { Blogs (e.g., CosplayDad, } \\
\text { cosplay.ph), Cosplayer } \\
\text { Facebook profiles (e.g, Kamui } \\
\text { Cosplay, Yaya Han), niche } \\
\text { media (e.g., kotaku, buzzfeed). }\end{array}$ & $\begin{array}{l}12 \text { blogs } \\
9 \text { profiles } \\
(16 \text { double- } \\
\text { spaced pages of } \\
\text { notes) }\end{array}$ & $\begin{array}{l}\text { Understanding deeply } \\
\text { engaged cosplayers and their } \\
\text { online interactions. Learning } \\
\text { from tutorials. Discerning } \\
\text { construction of cosplay fame. }\end{array}$ \\
\hline $\begin{array}{l}\text { Newspaper } \\
\text { articles }\end{array}$ & $\begin{array}{l}\text { E.g., New York Times, Wired, } \\
\text { The Guardian, Financial Times. }\end{array}$ & $\begin{array}{l}10 \text { articles, } 67 \\
\text { double-spaced } \\
\text { pages }\end{array}$ & $\begin{array}{l}\text { Contextualizing cosplay } \\
\text { within marketplace and } \\
\text { understanding emerging } \\
\text { mainstream interest } 2010 \text { and } \\
\text { after. Studying advocacy } \\
\text { practices. }\end{array}$ \\
\hline Documentaries & $\begin{array}{l}\text { "Cosplay! Crafting a Secret } \\
\text { Identity" (WPBA); "Comic- } \\
\text { Con Episode IV: A Fan's } \\
\text { Hope" (Mutant Enemy, Thomas } \\
\text { Tull Productions, Warrior } \\
\text { Poets); "My Other Me: A Film } \\
\text { About Cosplayers" (M.O.D. } \\
\text { Entertainment and High Deaf } \\
\text { Productions). }\end{array}$ & 3 films & $\begin{array}{l}\text { Identifying cosplay as an } \\
\text { overall phenomenon and } \\
\text { gaining deeper knowledge of } \\
\text { embedded entrepreneurs. }\end{array}$ \\
\hline
\end{tabular}

